\title{
Reciprocal relationships in tax compliance decisions
}

\author{
C. Bazart ${ }^{\mathrm{a}, *}$, A. Bonein ${ }^{\mathrm{b}}$ \\ ${ }^{a}$ LAMETA, University of Montpellier 1 - Av. Raymond DUGRAND, C.S. 79606, 34960 \\ Montpellier Cedex 2. France. Phone +33(0) 434432493 , Fax +33 (0) 499612940 \\ ${ }^{b}$ CREM, University of Rennes 1 - 7 Place Hoche, C.S. 86514, 35065 Rennes Cedex. \\ France. Phone: +33(0) 223233 540, Fax +33(0) 223233509
}

\begin{abstract}
Reciprocity considerations are important to the tax compliance problem as they may explain the global dynamics of tax evasion, beyond individual tax evasion decisions, toward a downward or upward spiral. To provide evidence on reciprocity in tax compliance decisions, we have conducted a laboratory experiment in which we introduced two types of inequities. The first type of inequity is called vertical, because it refers to inequities introduced by the government when it sets different fiscal parameters for identical taxpayers, while the second type of inequity is called horizontal because it refers to the fact that taxpayers may differ in tax compliance decisions. In this setting, taxpayers may react to a disadvantageous or advantageous inequity through negative or positive reciprocal behaviors, respectively. Our results support the existence of negative and positive reciprocity in both vertical and horizontal cases. When both inequities come into play and may induce reciprocal behaviors in opposite directions, the horizontal always dominates the vertical.
\end{abstract}

Keywords: Behavioral economics; Experimental economics; Fairness; Tax evasion; Tax compliance JEL classification: H26, C91.

PsychoINFO: 2300, 2900, 3000, 4200.

\footnotetext{
${ }^{*}$ Corresponding author

Email addresses: cecile.bazart@lameta.univ-montp1.fr (C. Bazart), aurelie.bonein@univ-rennes1.fr (A. Bonein)
} 


\section{Introduction}

The tax compliance decision has been under study since the seminal theoretical work of Allingham \& Sandmo (1972). This work was rapidly followed by several economic and psychological studies that underlined the relevance of fairness considerations, in explaining tax evasion behavior (including Spicer \& Becker, 1980; Cowell, 1992; Bordignon, 1993; Falkinger, 1995; Kirchler, 2007; Torgler, 2007). There are several sources of unfairness, caused by differences in: tax policy parameters, levels of public goods provided or differentiated opportunities and levels of compliance among taxpayers. These can be regarded as related to the two main relationships at work in the study of tax evasion. The first relationship is between the public sector and taxpayers, as taxation implies a compulsory contribution by individuals to public sector funding (Alm et al., 1993a; Torgler, 2003). The second relationship is among taxpayers, as taxation also implies a collective and fair contribution by citizens to finance the government. Until now, these two relationships have been studied separately in the literature with the aim of confirming whether unfairness acts as a potential factor that neutralizes feelings of guilt and pushes taxpayers towards more evasion. Our work also addresses the consequences of perceived unfairness on tax evasion decisions and the overall dynamics of tax evasion.

Thus, a first wave of the literature focuses on the unfairness of the tax system itself, which alters taxpayers' behavior (Cowell, 1992; ${ }^{1}$ Falkinger, 1995). This is in line with the Frey (1997) and Feld \& Frey (2010) works on the crowding out of tax compliance as a civic virtue when government policies are perceived as unfair. In this case, initially honest taxpayers may start evading their taxes and evaders may increase their evasion activities. The intrinsic motivation of individuals is fueling a new line of research on ways to explain the compliance levels observed in experiments (Alm et al., 1992). Some studies have focused on the impact of tax rates on evasion activities, including Fortin et al. (2007). In their experiment, some taxpayers were taxed at a higher tax rate than the mean tax rate of their reference group, and they concluded that this generates evasion. Other research has focused on redistribution through the provision of public goods (Cowell \& Gordon, 1988; Alm et al., 1992; Barone \& Mocetti, 2011) and its impact on the per-

\footnotetext{
${ }^{1}$ Cowell (1992), due to risk aversion specifications, concludes that reducing the fairness of the system increases honesty.
} 
ceived fairness and legitimacy of governments in collection taxes. Finally, some studies linked tax morale to trust in governments and votes on tax policies (Alm et al., 1993b; Torgler, 2003; Hug \& Spörri, 2011).

Nevertheless, unfairness may also arise because of some taxpayers' decisions to underreport and evade their taxes while others pay honestly. Some earlier studies already linked taxpayers' decisions, that is, individual decisions become somehow conditional on what the others do, either in terms of frequency or extent of evasion (see Gordon, 1989; Bordignon, 1993; Myles \& Naylor, 1996; Alm \& McKee, 2004; Alm, 2012). These studies show that, under strong social norms, taxpayers face a disutility from being dishonest: for Gordon (1989), guilt in terms of disutility rises with evasion; for Bordignon (1993), taxpayers' intrinsic motivation to pay taxes decreases the more the others evade. This may be complicated by differences in individual moral codes, ethics and propensities to conform (Myles \& Naylor, 1996; Sandmo, 2005; Frey \& Torgler, 2007; Dell'Anno, 2009; Traxler, 2010). More recently, Lefebvre et al. (2011), experimentally showed that, while examples of low compliance tend to increase tax evasion, examples of high compliance have no influence. Our work is in line with this research, but we study simultaneously vertical and horizontal relationships.

Indeed, while self-centered individuals do not care about such inequities, reciprocally oriented individuals do and may be induced to react against them. As argued five decades ago by Gouldner (1960), most societies endorse a norm of "generalized reciprocity", according to which individuals should help those who have helped them and penalize those who have failed to cooperate. From this idea, several mainly theoretical and experimental works, were conducted to highlight both the existence and the relevance of reciprocal behaviors (see Fehr \& Gächter, 2000b for an overview). This research indicates the co-existence of different types of individuals and several forms of reciprocity, the most popular of which is "strong reciprocity". In this case, reciprocity is seen as a conditional behavior, where, in response to kind (unkind) actions, individuals are frequently much nicer (meaner) than the self-interest model would predict (Gintis, 2000). Individuals are not motivated by future material payoffs; they are viewed as moral and emotional reciprocators. One of the main field of study of reciprocal behaviors is related to the contribution to public goods. For example, Fehr \& Gächter (2000a) conducted a public goods game experiment that allowed for costly punishment of free-riders. They showed that, free-riders are heavily punished even if it is costly to and does not provide any material benefits for the punisher. 
Moreover, the existence of an opportunity for costly punishment leads to a large increase in cooperation levels. Fischbacher et al. (2001) also ran an experiment in this vein, but used the strategy method to evaluate complete individual strategy profiles. They found that, even if there was no opportunity for costly punishment, the contribution of individuals was positively related to the average contribution of others, when these latter increased. Such behaviors may be easily transposed to the tax evasion setting. For instance, if a taxpayer observes that other taxpayers evade taxes, he may be more inclined to evade as well, as to punish free-riders.

Recently, Schnellenbach (2010) provided this analysis of tax evasion through reciprocal reactions to unfairness. He stated that, because there are at least two potential sources of unfairness, there are symmetrically two types of reciprocity at work: vertical as well as horizontal reciprocal reactions may occur in the tax evasion decision. In the former case, taxpayers evade taxes to retaliate against a non-cooperative and unfair government. In the latter case, one individual's evasion increases if he or she believes that other taxpayers also evade. Moreover, the dynamics of tax evasion towards an upward spiral of evasion as individuals reciprocate is explained.

Our work follows that of Schnellenbach (2010), because we attempt to test the existence, nature and relative weights of vertical and horizontal reciprocal reactions in reporting decisions through a laboratory experiment. Nevertheless, our approach differs in that we allow for disadvantageous and advantageous inequities in both relationships, which respectively worsens or improves a taxpayer's perceived situation and potentially induces negative or positive reciprocal behaviors. The intuition is that taxpayers use tax evasion to restore fairness in any case. Our goal is to characterize the reactions of taxpayers and to offer empirical support for reciprocal punishment or cooperation in each case. We also aim to detail the link between vertical and horizontal unfairness, as we agree with Schnellenbach (2010) on: the heterogeneity of taxpayers' type in the population, the intuitive role of guilt in the tax evasion decision, and the potential rationalization and neutralization of this feeling of guilt when tax evasion is seen as a widespread practice among citizens. However, we also believe that guilt increases, at least for some individuals, when they perceive that very few taxpayers fail to pay their taxes. Individually and socially, tax evasion is then seen as a morally reprehensible practice. While theoretical studies either specify a fairness measure in the utility function (Cowell, 1992) or introduce inequity in the amount of public goods provided (Falkinger, 1995), we have restricted ourselves to vertical un- 
fairness arising from different tax rates to induce vertical reciprocity, in line with Fortin et al. (2007). So we excluded redistribution from our analysis to avoid having two potential sources of unfairness. In line with Bordignon (1993), we decided to build the horizontal inequity scheme by providing past exogenous information on fellow citizens' average declaration to induce horizontal reciprocity. We derive support for this study from Myles \& Naylor (1996) as we assume that the dynamics of tax evasion is fueled by social interactions and that taxpayers shift from honesty to evasion upon crossing a given threshold. This threshold is assumed to vary and depends on the sensitivity of taxpayers to the unfairness. Last, note that, in this work, we discuss neither the validity of the reciprocity approach for evasion activities, which we take from Schnellenbach (2010), nor the kind of fairness benchmark individuals use to make their decisions.

The remainder of this paper is organized as follows. Section 2 presents the theoretical predictions of taxpayers' decision. Section 3 exposes the experimental design and procedures. Section 4 presents the results and Section 5 provides our conclusions.

\section{Reciprocity and tax compliance: Theoretical predictions}

We have developed a simple analytical framework to analyze the existence of reciprocal behaviors resulting from the introduction of two types of inequities that distort a fair situation (benchmark). We will refer to these two inequities as vertical inequity on the one hand, and horizontal inequity on the other, because they refer, respectively, to the vertical relationship between taxpayers and the government or the horizontal relationship existing between any taxpayer and his fellow citizens. ${ }^{2}$ To that sense, we follow Schnellenbach (2010), according to whom, "If this interdependence is indeed reciprocityrelated, then some notion of fairness will be needed as a benchmark, with

\footnotetext{
${ }^{2}$ The notions of vertical inequity and horizontal inequity used in this paper should not be confused with the concepts of vertical/ horizontal inequity given in standard public economics textbooks. Usually, "vertical equity" is the principle that individuals with a greater ability to pay should pay greater amount of taxes while in our work we call vertical inequity the inequity applied to identical taxpayers but associated with the vertical relationship since unfairness of the tax system can be attributed to the government. In the same way, "horizontal equity" is the principle that individuals with equal ability to pay should pay equal taxes. In our paper horizontal inequity appears ex post, due to differences in reported income.
} 
deviations from the benchmark evoking negative reciprocity", p.59. From the benchmark case where neither vertical nor horizontal reciprocity may be induced, we have studied three different cases: (i) the vertical case, where only vertical reciprocity may appear; (ii) the horizontal case, where only horizontal reciprocity may play a role in reporting decisions; and, lastly,(iii) the simultaneous case of vertical and horizontal inequities where vertical and horizontal reciprocities may co-exist. All theoretical predictions are determined considering the reporting decision of taxpayer $i$ through the maximization of his expected utility at period $t$.

\subsection{Benchmark}

The benchmark case, by assumption, corresponds to the situation of perfect perceived fairness of the system. In what follows, we assume that tax households are composed of only one taxpayer, benefiting of one and identical income level $W$ and taxed at the same tax rate $\theta$. We will also restrict the set of individual fiscal characteristics to the unique real income variable. Additionally, taxpayers have no knowledge of tax evasion activities by their fellow citizens. Thus, the expected utility of taxpayer $i$ at period $t$ can be written as:

$$
E U_{B, i}=(1-\rho) U\left(W-\theta X_{i}\right)+\rho U\left(W-\theta X_{i}-\left(W-X_{i}\right) \theta \pi\right)
$$

where $\rho$ is the exogenous probability of audit, $\pi$ is the fine rate on evaded taxes with, $\pi>1$, as it simultaneously captures the repayment of due taxes and the extra burden due to the penalty, following Yitzhaki (1974). In what follows, we assume that $U$ is a linear utility function.

Maximizing taxpayer $i$ 's expected utility allows us to say that:

Hypothesis 1. In the absence of obvious inequity, if $\pi \geq \frac{1}{\rho}$ then riskneutral taxpayers report their income truthfully.

Nonetheless, various inequities may exist among taxpayers. Here, we subsequently focus on vertical inequity, horizontal inequity and we combine the two to conclude.

\subsection{Vertical reciprocity}

Vertical reciprocity may arise when taxpayers face an inequity generated by the government itself. It refers to the unfairness of the tax system and 
results from differences in tax rules and fiscal parameters for identical taxpayers. For the sake of simplification, the sole fiscal parameter that varies is the tax rate $\theta$. We consider only two taxpayers, each representing one group $\{i, j\}$. The vertical inequity, denoted by $\phi$, results from the co-existence of two different tax rates $\theta_{i}$ and $\theta_{j}$. This inequity may influence tax reports, depending on the individual's sensitivity to the unfairness of the tax system, denoted by $\alpha_{i} \geqslant 0$. To that end, a psychological component $c$ is introduced to account for any perceived unfairness:

$$
c=v_{i}(\phi)=1+\alpha_{i}\left(\theta_{i}-\theta_{j}\right) X_{i}
$$

where $v_{i}$ represents the motivations for vertical reciprocity. As a consequence the expected utility of taxpayer $i$ at period $t$ becomes:

$$
\begin{aligned}
E U_{V I, i}= & (1-\rho)\left(W-\theta_{i} X_{i}\right)+\rho\left(W-\theta_{i} X_{i}-\left(W-X_{i}\right) \theta_{i} \pi\right) \\
& -\left(1+\alpha_{i}\left(\theta_{i}-\theta_{j}\right) X_{i}\right)
\end{aligned}
$$

From this setting, we consider two sub-cases. Either taxpayer $i$ is taxed at a higher rate than taxpayer $j$ and $\theta_{i}>\theta_{j}$; or it is the reverse and $\theta_{i}<$ $\theta_{j}$. In the first case, taxpayer $i$ suffers from the inequity (disadvantageous inequity) and may react by evading (negative vertical reciprocity) if $\alpha_{i}$ is high enough. While in the latter case, taxpayer $i$ benefits from the lower tax rate (advantageous inequity) that induces him to increase his reported income (positive vertical reciprocity). ${ }^{3}$

Hypothesis 2. Disadvantageous inequity in tax rates induces negative vertical reciprocity, while advantageous inequity in tax rates leads to positive vertical reciprocity.

\subsection{Horizontal reciprocity}

Here horizontal inequity arises from differences among taxpayers due to their different choices in terms of reported income. As a consequence, honest taxpayers bear the tax burden when others evade. Then, assuming a fair

\footnotetext{
${ }^{3}$ Proofs are available in the Appendix 1.
} 
fiscal system, there is an ex post inequity between identical taxpayers. We have considered that, in real life, taxpayers mainly have ex post information on what others (family, friends or even colleagues) do in terms of reporting income to the tax authorities. It is also obvious that such information is usually not precise, as evasion is an illegal activity. In most cases, it is an ex post overall estimate of evasion activities by relatives or fellow citizens, because there is only an approximate knowledge of the existence of past tax evasion activities, but no idea as to the concerned amounts. As a consequence, we assume that taxpayers are informed about the mean reporting behavior of their fellow citizens at the previous period. They are able to observe any difference between their own reported income $X_{i, t-1}$ and the average reported income of others within the same group $\bar{X}_{-i, t-1}$ at the end of the period. In this context, the psychological component $c$ takes into account the effect of having reported a different income than the average reported income of other group members:

$$
c=\eta_{i}(\xi)=1+\delta_{i}\left(X_{i, t-1}-\bar{X}_{-i, t-1}\right) X_{i, t}
$$

where $\xi$ denotes the horizontal inequity, $\eta$ the motivation for horizontal reciprocity that depends on the taxpayer's sensitivity parameter to inequity $\delta_{i} \geqslant 0$. The expected utility of taxpayer $i$ at period $t$ can be written as follows:

$$
\begin{aligned}
E U_{H I, i, t}= & (1-\rho)\left(W-\theta X_{i, t}\right)+\rho\left(W-\theta X_{i, t}-\left(W-X_{i, t}\right) \theta \pi\right) \\
& -\left(1+\delta_{i}\left(X_{i, t-1}-\bar{X}_{-i, t-1}\right) X_{i, t}\right)
\end{aligned}
$$

Again, we face two symmetric cases. In the first case, taxpayer $i$ has reported a higher income than the average of other group members i.e., $X_{i, t-1}>\bar{X}_{-i, t-1}$ and inequity is thus at his disadvantage. If taxpayer $i$ wants to become closer to the average of his other group members, he will decrease his reported income at period $t$ (negative horizontal reciprocity). In the second case, taxpayer $i$ has reported a lower income than what his other group members have reported on average i.e., $X_{i, t-1}<\bar{X}_{-i, t-1}$ and inequity is at his advantage. If taxpayer $i$ wants to become closer to the average of his other group members, he will increase his reported income at period $t$ 
(positive horizontal reciprocity). ${ }^{4}$ As a result, the following prediction can be made:

Hypothesis 3. Disadvantageous inequity in reported income induces negative horizontal reciprocity, while advantageous inequity leads to positive horizontal reciprocity.

\subsection{Vertical and horizontal reciprocities}

Horizontal and vertical inequities may co-exist and thus may interact. In this case, the psychological component $c$ that stems from both inequities is written as follows:

$$
c=v_{i}(\phi)+\eta_{i}(\xi)
$$

As a consequence, the overall effect depends on the type of inequities at work (see Table 1).

[Table 1 about here.]

When inequities go in the same direction, conclusions are easy to draw. On the one hand, inequity in tax rates is assumed to increase the evasion of taxpayers who suffer from a disadvantageous vertical inequity (negative vertical reciprocity). Simultaneously, differences in reported income are expected to decrease any feelings of guilt by potential evaders who suffer from a disadvantageous horizontal inequity and have the sense that some of their fellow citizens evade their taxes (negative horizontal reciprocity). Both effects should thus reinforce each other. On the other hand, taxpayers who benefit from an advantageous vertical inequity tend to be fully honest (positive vertical reciprocity). In addition, advantageous horizontal inequity may increase any feelings of guilt because taxpayer $i$ has the sense that he evades more than his fellow citizens (positive horizontal reciprocity). Both effects should thus reinforce each other.

Hypothesis 4. When both inequities act in the same direction, they reinforce each other, leading to the induced reciprocal behavior.

\footnotetext{
${ }^{4}$ Proofs are available in the Appendix 1.
} 
But, when inequities act in opposite directions, it is impossible to draw any conclusions on their global effect on subsequent reported income decisions (see Table 1). Our experimental study aims at exploring the effects of each type of inequity separately on income reporting decisions and to analyze whether vertical or horizontal inequity prevails when both work simultaneously but in opposite directions.

\section{Experimental design and procedures}

\subsection{Games}

An experimental session consists of 3 independent games: the tax game, the risk game and the inequity game. The main focus of this study is to highlight the determinants of reported income when various inequities occur. To that end, the first part of our experimental design corresponds to the tax game. Because previous experiments have underlined that tax evasion is related to risk aversion, we elicited our participants' risk preferences after the tax game using Dohmen et al. (2011)'s procedure. Finally, to analyze to what extend individuals are sensitive to inequity, and if this sensitivity affects reported income decisions, we also elicited pro-social preferences with the procedure of Bartling et al. (2009).

\subsubsection{The tax game}

Because our focus is on tax compliance decisions, we did not introduce redistribution through the provision of public goods financed by tax payments. So tax payments are not transferred to the taxpayers in any way. This means that the tax game is a pure declaration game that is repeated in different contexts characterized by different types of inequity that distort the benchmark case of perfect perceived fairness: vertical inequity, horizontal inequity and, both types of inequity simultaneously.

At the outset of the game, participants are presented with a screen informing them of their individual income and the tax policy parameters (i.e., fine, audit and tax rates). Parameters are set such that they deliver theoretical predictions in accordance with the above hypotheses under some restrictions regarding the parameters of sensitivity to inequities. ${ }^{5}$ More precisely, in each period, participants are provided with a constant income of

\footnotetext{
${ }^{5}$ See the Appendix 2 for details.
} 
$X=100$ points. ${ }^{6}$ We set the fine rate at $\Pi=350 \%$ (i.e., participants have to pay evaded taxes plus a penalty of $250 \%$ of unpaid taxes in the case of an audit). Audits are assumed to be random and perfect. Audits occur with an announced probability that is also fixed for all sessions at $\rho=1 / 3$. We used the same random sequence of audit to facilitate data comparisons between experimental sessions. Audits apply only to current reported income, not to previous (or future) periods. In our experimental design, the tax rate is the sole tax policy parameter to vary across experimental treatments to introduce vertical inequity among taxpayers, $\theta=\{20 \% ; 30 \% ; 40 \%\}$.

At the time they make their decisions, participants have to determine the amount of income they will self-report to the tax authorities. They can choose to report any integer amount from 0 to 100. At the end of each period, they are informed about whether they have been audited and of their net payoff. If the participant has an under-reported tax liability and is audited, then a fine is imposed.

This process is repeated over 20 periods, each representing a tax year. Participants are informed that they will be paid their after-tax earnings, obtained in 5 out of the 20 periods, at the end of the entire experiment. The randomly chosen periods are the same for all participants in the same experimental session. The earned points are converted into Euros at the end of the experiment, and the exchange rate used was 100 points $=3.80$ Euros.

From this setup, 6 experimental treatments were run in a between-subject design. In each treatment, groups of 6 subjects are formed and group composition remains constant throughout the tax game. The first treatment (benchmark) provides the baseline setting where all members of a group have the same income and fiscal policy parameters and are not provided with any kind of social information about the choices of other group members. In the second treatment, we introduce a vertical inequity in the sense that half the members of a group have a tax rate equal to $30 \%$, while the others have a tax rate of $20 \%$. Because a tax rate equal to $30 \%$ (which is the same as the one used in the benchmark treatment) is higher than $20 \%$, we call this treatment the high vertical inequity treatment (HV-I). The results obtained from this treatment allow us to study the impact of a disadvantageous vertical inequity on the reporting decisions. The third treatment is the same as the second one, except that the tax rate of $30 \%$ is the lowest (so half

\footnotetext{
${ }^{6}$ The term points refers to the experimental currency unit.
} 
of group members have a tax rate equal to $30 \%$, while the others have a tax rate of $40 \%$ ). This treatment is called low vertical inequity (LV-I) and permits us to analyze the impact of an advantageous vertical inequity. In the fourth treatment, we introduce another form of inequity: a horizontal inequity. We call this treatment horizontal inequity (H-I). More precisely, at the end of each period, when participants are informed about whether they have been audited and of their net payoff, they also learn the average income reported by the other members of their group. Depending on the level of reported income and the average reported income of the other group members, we are able to study the impact of disadvantageous and advantageous horizontal inequities. Finally, the last two treatments mixed vertical and horizontal inequities: the fifth treatment includes the high vertical inequity treatment as well as additional information regarding the average income reported by other group members (H-HV-I) and the sixth treatment mixes the low vertical inequity treatment and the horizontal inequity (H-LV-I). These last two treatments aim at examining which type of inequity (i.e., vertical or horizontal) dominates the other when theoretical predictions are in conflict. The used experimental treatments and parameters are reported in Table 2 while the resulting numerical thresholds of individual sensitivity towards vertical and horizontal inequities for theoretical predictions to be confirmed are exposed in the Appendix 2.

[Table 2 about here.]

\subsubsection{The risk game}

In this game, participants had to make 20 successive choices between 2 options. The first option is a safe option that varies from row to row, from 0 to 19 points, by increments of 1 point. The second option is a lottery that remains constant: there is a 50 percent chance of winning 0 points and a 50 percent chance of winning 30 points (see Table 7 in the Appendix $3)$. The switching point between the two options informs us about the risk attitude of the participants. Risk-neutral participants should switch from the lottery to the safe option at 15. Risk-loving participants should choose the safe payment when the offered safe option is higher than 15, while risk-averse participants should prefer the safe option for safe payments lower than 15 . In this way, we are able to compute individual risk preferences parameters and subsequently see whether risk preferences and evasion decisions are related. Regarding participants' earnings, they are informed that, after having made 
their decisions, one of the rows will randomly be selected for payment and that they will be paid according to their choice. The selected row is, again, the same for all participants. In line with Dohmen et al. (2011), to ensure incentive compatibility, participants are informed that a random device will determine whether they are paid for this experiment. The chance of winning was $1 / 8$ and the exchange rate used was 3.7 points $=1$ Euro.

\subsubsection{The inequity game}

This game aims to elicit individual pro-social preferences to study whether they affect honesty behaviors, especially in case of inequity in the level of income reported by other group members. To that end, we follow the experimental design of Bartling et al. (2009). Subjects go through four simple binary distributional choices, affecting both their own earnings and the earnings of another anonymously matched participant (see Table 8 in the Appendix 4). The first two distributional choices address aversion to advantageous inequity (aheadness aversion) in which participants have to choose between egalitarian and unequal distributions that favors them. In the first choice, choosing equal payoff implies no financial cost for the decision-maker, contrary to the second distributional choice, which implies a decrease in his earnings. The remaining two choices address aversion to disadvantageous inequity (or behindness aversion) in which participants have to choose between egalitarian and unequal distributions that favors the anonymous partner. In the first case, by choosing the equal distribution, the decision-maker can decrease the payoff of the anonymous partner without incurring any cost. Conversely, in the last distributional choice, if the participant chooses the equal distribution, he diminishes the other's earnings, but simultaneously his own earnings slightly decrease. From this setting, we say that participants are aheadness averse if they consistently choose the equal distribution in the first two choices. In the same way, they are behindness averse if they select the egalitarian distribution in the last two distributional choices. Finally, participants who always choose the equal distribution of earnings have egalitarian preferences. In line with Bartling et al. (2009), only one of the four binary distributional choice is randomly selected at the end of the experiment for payment and it is the same for all participants. The exchange rate used in this game was 8 points=1 Euro. 


\subsection{Participants}

Our experiment was conducted at the LABEX-EM Institute (Laboratoire d'EXperimentation en Economie et Management) at the University of Rennes 1. The experiment was computerized using Z-tree (Fischbacher, 2007). Participants were recruited from a pool of undergraduate students using the online Recruiting System for Experimental Economics (ORSEE) (Greiner, 2004). We ran two sessions per experimental treatment of the tax game, with 24 participants per session, so that we have 4 independent observations per session. Overall, 288 subjects participated.

Upon arrival at the laboratory, each participant was randomly assigned to a computer located in a cubicle and was not allowed to communicate with other participants. Paper instructions relative to the first part (i.e., the tax game) were distributed and read aloud by the experimenter. ${ }^{7}$ Once the first game ended, the subjects took part in the risk and inequity games (the order of these two games was reversed in half of the experimental sessions). For these two games, the instructions were conveyed by a series of computer screens that the participants read at their own pace. Clarification questions were addressed after participants completed reading the instructions and participated in two practice exercises, before the game started. Participants were told at the beginning of the session that (i) all responses were anonymous, (ii) their payment would be equal to the sum of the earnings obtained in the 3 games plus a show-up fee of 3 Euros and (iii) their payments would be made in private at the end of the session. While the money-release forms were being prepared, participants answered a questionnaire aimed at recording individual demographic characteristics (see Table 3). Participants who finished filling out the questionnaires signed their money-release forms and were given their payoff. The experiment lasted 90 minutes on average, and earnings averaged 16 Euros.

[Table 3 about here.]

\footnotetext{
${ }^{7}$ Instructions are provided in the Appendix 6 .
} 


\section{Results}

\subsection{Descriptive analysis}

\subsubsection{Self-reported income under equal tax rates and without social informa-} tion

Table 4 indicates that the average reported income over the 20 periods is equal to 66.74 points. However, this mean conceals strong variations in the level of reported incomes during the 20 periods, as Figure 1 shows. These results suggest, first, that at least some taxpayers evaded taxes and, second, that taxpayers are influenced by the results of the previous period (occurrence of audit, ...). This is contrary to theoretical predictions based on self-material interest and the individual rationality of risk-neutral taxpayers since the experimental parameters should have led to a full contribution environment. ${ }^{8}$ A closer look at individual strategy profiles highlights that, overall, 48.54\% of subjects honestly reported their income (Hypothesis 1 is satisfied) while $19.58 \%$ of taxpayers were full evaders. The remainder corresponded to partial evasion cases (i.e., self-reported income between 0 and 100 not included).

[Table 4 about here.]

[Figure 1 about here.]

Result 1: A great heterogeneity of individual behaviors is observed from full evasion to full honesty.

\subsubsection{Self-reported income under inequity in tax rates and without social information}

Once we introduced vertical inequity, two situations had to be considered: either taxpayers had the highest tax rate, or they had the lowest one. Looking first at disadvantageous vertical inequity (i.e., HV-I treatment with $\theta=$ $\{30 \% ; 20 \%\})$, we naturally observed that those enjoying the $20 \%$ tax rate reported, on average, a higher income than those having the $30 \%$ tax rate (see Table 4; Mann-Whitney U test: $z=3.898, p=0.0001) .{ }^{9}$ Regarding the

\footnotetext{
${ }^{8}$ The full contribution environment refers to the situation where the theoretical prediction is that all taxpayers report truthfully their income.

${ }^{9}$ Because comparisons of reported income by taxpayers enjoying the lowest or the highest tax rates is not the purpose of this study, we do not go deeper into this issue.
} 
effects of inequity in tax rates on reported income by taxpayers with a $30 \%$ tax rate, we note that the average self-reported income differed significantly in case of disadvantageous inequity from that observed in the benchmark treatment (Mann-Whitney U test: $z=2.225, p=0.0261$ ). Suffering from the highest tax rate led to a decrease in the level of reported income while the level of the applied tax rate per se was the same as the one used in the benchmark treatment. A comparison of the average income reported by taxpayers with a $30 \%$ tax rate in the LV-I treatment and the HV-I treatment strengthens this result (Mann-Whitney U test: $z=2.998, p=0.0029$ ). Benefiting from the lowest tax rate or suffering from the highest one strongly impacts taxpayers' reported income, although the level of the applied tax rate was the same. This finding is in line with Hypothesis 2, according to which, in case of disadvantageous inequity, highly sensitive taxpayers will not report fully their income and express negative reciprocity. An examination of individual strategy profiles revealed an increase in the proportion of evaders (51.46\% in the benchmark and $57.92 \%$ in the HV-I treatment), even if the difference in the level of self-reported incomes in case of evasion was not statistically significant (35.36 points and 34.27 points; Mann-Whitney U test: $z=2.259, p=0.7956)$. So, the difference in average self-reported income between the two experimental treatments has to be mainly explained by a decrease in the number of honest taxpayers that leads to a decrease in the level of reported income and to an upward spiral of evasion in the long run.

Result 2: Disadvantageous inequity in tax rates leads to an increase in the number of evaders and a subsequent decrease in the collection of taxes in the long run.

We now turn to advantageous inequity in tax rates, that is, the LV-I treatment, with $\theta=\{30 \% ; 40 \%\}$. As previously observed, average self-reported income differed significantly according to the applied tax rate (see Table 4; Mann-Whitney U test: $z=3.898, p=0.0001$ ). This is also confirmed by the third panel at the top of Figure 1. If we focus on taxpayers with a $30 \%$ tax rate, no significant difference appears between the incomes reported in the benchmark treatment and the ones reported by taxpayers with a 30\% tax rate in the LV-I treatment (Mann-Whitney $\mathrm{U}$ test: $z=-1.179, p=0.2385$ ). In addition, a clean analysis of individual strategy profiles revealed that the proportion of honest taxpayers increased slightly (from $48.54 \%$ to 50.21\%, see Table 4), in line with the theoretical prediction summarized in Hypoth- 
esis 2. The number of evaders, then, decreased and the level of self-reported income in the case of evasion was also higher (35.36 points in the benchmark treatment and 39.83 points in the LV-I treatment with $\theta=30 \%$; MannWhitney U test: $z=-1.665, p=0.0960)$. Benefiting from the lowest tax rate does not induce most taxpayers to truthfully report their income. It only induces evaders to self-report higher income compared to the decisions made by evaders in the benchmark treatment. One can conclude that at least some taxpayers manifest a form of positive reciprocity. So, it seems that having a lower tax rate than some other group members leads some taxpayers to greater honesty while still not reporting their entire income. In the long run, this advantageous inequity in tax rates may allow the tax authority to collect more taxes.

Result 3: Advantageous vertical inequity does not induce a strong increase in fully honest behaviors but does decrease the level of evasion, which facilitates the collection of taxes in the long run.

\subsubsection{Self-reported income under equal tax rates and with social information}

Looking at horizontal inequity, taxpayers learn the average reported income of other group members $\bar{X}_{-i, t-1}$ at the end of the period $t-1$. It results that, depending on the average level of reported income, some taxpayers may suffer from inequity $\left(X_{i, t-1}>\bar{X}_{-i, t-1}\right)$ while others may benefit from it $\left(X_{i, t-1}<\bar{X}_{-i, t-1}\right)$. Therefore, we examine whether taxpayers consider the average reported income of other group members at period $t-1$ when making their current decision. For instance, do taxpayers adjust their next reported income up or down to come closer to the average income reported by other group members at the previous period? Note that the information displayed to taxpayers did not permit them to determine the individual choices of the 5 other members of their group and only provided an aggregate approximation of what other group members did. In this setting, even if the average reported income did not differ significantly from that observed in the benchmark treatment (see Table 4; Mann-Whitney U test: $z=0.359$, $p=0.7198$ ), less extreme behaviors (full evasion or full honesty) were observed. This could suggest that taxpayers adjust their next reported incomes depending on the average reported income of other group members, without being fully honest or dishonest. Examination of individual strategy profiles revealed that, when the reported income was above other group members' 
average reported income (60.73\% of situations), $55.40 \%$ of the next reported incomes decreased. Conversely, when the reported income was below other group members' average reported income (38.85\% of situations), $79.08 \%$ of the next reported income increased. The direction of adjustment depended on whether taxpayers were above or below the average reported income by other group members, while the strength of such an adjustment may depend on pro-social preferences. To go deeper into this issue, we used the type of preferences elicited from the inequity game experiment. This game allowed us to characterize taxpayers as behindness averse, aheadness averse, egalitarian or other, if their decisions corresponded to none of the previous individual strategies. The results obtained in the inequity game highlight that, among the subjects pool of the H-I treatment, most taxpayers $(87.5 \%)$ expressed aheadness aversion, $18.75 \%$ expressed behindness aversion, $12.5 \%$ had egalitarian preferences and $6.25 \%$ made choices that were not in accordance with any of these three strategies (see Table 5). From that, we computed the Spearman rank correlation coefficients to highlight both the direction and the strength of the correlation between the reported income at period $t$ and the average reported income of other group members at period $t-1$. From the results reported in Table 5, as expected, both for taxpayers who expressed aheadness and behindness aversions, when they reported an income higher than the average of reported income by other group members, their reported income decreased significantly at the next period. In the same way, when they reported an income lower than the average of reported income by other group members, their reported income increased significantly at the next period. Such behavior is perfectly in line with Hypothesis 3, which describes negative reciprocal behaviors in case of disadvantageous inequity in reported incomes and positive reciprocal behaviors in case of advantageous inequity in reported incomes. A lower variability in reported incomes across the 20 periods, compared to the benchmark treatment, ensued (see Figure 1).

[Table 5 about here.]

Result 4: Some taxpayers consider the average self-reported income of their group to choose the income they will report in the current period. 


\subsubsection{Self-reported income under inequity in tax rates and with social infor- mation}

Finally, we looked at reported incomes when both vertical and horizontal inequities simultaneously occurred. From this setting, we first examined the case of horizontal and disadvantageous vertical inequities (i.e., H-HV-I treatment with $\theta$ equal to $30 \%$ or $20 \%$ ). Table 4 shows that average income reported by taxpayers with a $30 \%$ tax rate was higher than that reported in the H-I and the HV-I treatments for taxpayers with the $30 \%$ tax rate (MannWhitney U tests: $z=-7.801, p<0.0001$ and $z=-6.550, p<0.0001$ respectively). The following explains this result: at the end of each period, taxpayers learn the average of other group members' reported incomes, which included decisions made by both taxpayers with a $30 \%$ tax rate and those with a $20 \%$ tax rate. As we have previously seen, taxpayers with the lowest tax rate usually reported a higher income than others. This led to a higher average reported income compared to the H-I treatment, in which all taxpayers have a $30 \%$ tax rate. By considering such information during the decision-making process, taxpayers who were sensitive to the average of other group members' reported incomes tended to increase how much the income they report. If several taxpayers in the group act in this way, this will once again lead to an increase in the average reported income, and so on. This reasoning causes higher average reported incomes than those observed in the $\mathrm{H}-\mathrm{I}$ and HV-I treatments. Figure 2 confirms that, except in few periods, the average reported incomes by taxpayers with a $30 \%$ tax rate were higher in case of disadvantageous inequity in tax rates than without inequity. Again, individual strategy profiles strengthen this result. As reported on Table 4, we note a larger proportion of honest taxpayers and a lower proportion of full evaders. Moreover, when the reported income was above other group members' average reported incomes ( $64.16 \%$ of situations), both inequities were at the disadvantage of taxpayers. In this case, $43.51 \%$ of the next reported incomes were smaller, which corroborates the negative reciprocity assumed in Hypothesis 4. Even if less than half of taxpayers decreases the level of their next reported income, it is important to note that only $9.42 \%$ of the next reported incomes increased. Conversely, when taxpayers reported an income lower than the other group members' average, inequity in tax rates should lead to negative reciprocity while social information should induce positive reciprocity. In this case (32.29\% of situations), $75.48 \%$ of the next decisions consisted of a higher level of reported income, i.e., positive recipro- 
cal behaviors. One can conclude that, even if taxpayers suffer from a higher tax rate than some of the other taxpayers in their group, this does not induce them to evade. Conversely, they are more sensitive to the average income reported by other group members and try to come closer to it despite the fact that they have different tax rates. It follows that, horizontal inequity prevails and the effect of having a different tax rate vanishes. Finally, the correlation between the current reported income and the average reported income of other group members in the previous period corroborates both the direction of the adjustment and the strength of the relationship between the two (see Table 5).

The symmetric result is observed in case of advantageous inequity in tax rates (i.e., H-LV-I treatment with $\theta$ equal to $30 \%$ or $40 \%$ ). Table 4 shows that the average income reported by taxpayers with a $30 \%$ tax rate is, at first sight, strangely low when compared to that observed in the $\mathrm{H}-\mathrm{I}$ or in the LV-I treatments with a $30 \%$ tax rate (Mann-Whitney U tests: $z=6.515$, $p<0.0001$ and $z=4.557, p<0.0001$ respectively). To explain this finding, the previous argument holds: taxpayers with a $30 \%$ tax rate benefit from a lower tax rate than some of the other taxpayers in their group who have a $40 \%$ tax rate. In this case, the average reported income is lower due to the lower honesty of taxpayers with the $40 \%$ tax rate at the beginning of the game. This small average reported income induces taxpayers to decrease the next income they report compared to the H-I treatment, in which all taxpayers have a $30 \%$ tax rate. By considering such information during the decision-making process, taxpayers who are sensitive to the average of other group members' reported income tend to decrease the income they report. If several taxpayers in the group act in this way, this leads once again to a decrease in the average reported income, and so on. This reasoning leads to lower average reported incomes than those observed in the H-I and LV-I treatments (see Figure 2). Such adjustments are corroborated by the study of individual reported incomes. When reported income was below other group members' average (41.66\% of situations), we had both an advantageous inequity in tax rates and an advantageous horizontal inequity. In this case, $70 \%$ of the next reported incomes were higher which confirms our theoretical predictions (Hypothesis 4 of an increase in reported income when both inequities are at the advantage of taxpayer $i$ ). Conversely, when inequities worked in opposite direction (i.e., when reported income was above the other group members' average), the inequity in tax rates should lead to an increase in reported income (positive reciprocity) while the horizontal inequity 
should induce a decrease (negative reciprocity). This occurred in 57.29\% of situations, and we note that $53.09 \%$ of next reported incomes decreased while only $15.27 \%$ increased. Once again, this result suggests that horizontal inequity prevails. Our argument is also supported by the analysis of individual strategy profiles. As reported in Table 4, we note a lower proportion of honest taxpayers as well as a larger proportion of full evaders. This result suggests that taxpayers are more sensitive to other taxpayers' decisions than to differences in tax rates. Indeed, even if they benefit from an advantageous inequity in tax rates, the behavior of other taxpayers induces them to lower their next reported income, so they can come closer to the others, and removes the effect of vertical inequity. Such adjustments are supported by the computation of Spearman rank correlation coefficients between current reported income $\left(X_{i, t}\right)$ and average reported incomes by other group members in the previous period $\bar{X}_{-i, t-1}$ (see Table 5 ).

[Figure 2 about here.]

Result 5: When inequities work in the same direction, the corresponding reciprocal behavior prevails. Conversely, when inequities may induce reciprocal behaviors in opposite directions, the horizontal inequity always dominates the vertical one.

\subsection{Determinants of self-reported income}

To provide more detailed results on the determinants of self-reported income, we conducted some econometric analyses. We decided to use a dynamic panel regression model for three reasons. First, from data observation, we noticed that taxpayers vary considerably in their reported income choices. Second, taxpayers change their reported income from period to period. Third, taxpayers' decisions may be affected by other group members' average reported income in previous periods, when such information is available. Dynamic panel data analysis, following Arellano \& Bond (1991) and Blundell \& Bond (1998) seems therefore to be the most accurate method here. The proposed Generalized Method of Moments procedure is particularly designed for situations with few periods and many individuals. It allows us to control for independent variables that are potentially correlated with past and possibly current realizations of the error, with fixed effect, heteroskedasticity and autocorrelation within individuals. Thus, we specified 
a dynamic panel regression model for $X_{i, t}$, that is taxpayer's $i$ self-reported income in period $t$, which was modeled as depending on a number of observable explanatory variables, a specific group fixed-effect $\omega_{i, j}$, time fixed-effects $\zeta_{t}$ and an error term composed of a specific taxpayer fixed-effect, $\mu_{i}$ and an unobserved component $\epsilon_{i, t}$, as detailed in equation 7 :

$$
\begin{aligned}
X_{i, t}= & \beta_{0}+\sum_{p=1}^{3} \beta_{i} X_{i, t-p}+\psi_{i} \theta_{i}+\sum_{p=1}^{3} \lambda_{i}\left(\left|X_{i, t-p}-\bar{X}_{-i, t-p}\right|\right) \\
& +\sum_{p=1}^{3} \gamma_{i}\left(\text { Audit }_{t-p}\right)+\tau^{\prime} \mathbf{Z}_{\mathbf{i}, \mathbf{t}}+\omega_{i, j}+\zeta_{t}+\mu_{i}+\epsilon_{i, t}
\end{aligned}
$$

with $\bar{X}_{-i, t-p}$ the lagged value of the observed average income reported by other group members from periods $p$ to $t$. When information about the average of other group members' reported income was provided, we conducted separate regressions for reported income above or below the other group members' average. This formalization allowed us to separately study disadvantageous and advantageous horizontal inequities. The lagged values of individual reported incomes, average of the reported incomes of other group members and audits, were introduced to allow the model to capture the smoothness observed in the individual-subject reported income dynamics. $\theta_{i}$ is the value of the tax rate applied to taxpayer $i$ (i.e., $20 \%, 30 \%$ or $40 \%$ ). Finally, $\mathbf{Z}_{\mathbf{i}, \mathbf{t}}$ is a set of independent variables that allows us to control for socio-demographics characteristics (such as age, gender, risk attitudes and pro-social preferences). Results are reported in Table 6.

[Table 6 about here.]

We first looked at inequity in tax rates (i.e., columns 1 and 2). After having controlled for past reported incomes and audits, the level of tax rate remains a strong and negative determinant of reported income that corroborates our previous findings. We also note that having been audited has a negative and persistent effect on reported income. This means that, after having been audited, taxpayers believe that they will not be audited in the next periods and take the risk of reducing the level of the income they report to increase their after-tax income (bomb crater effect). Of course, the aftertax income is increased only if such taxpayers are not audited. Looking at the 
inequity in reported incomes among the group (horizontal inequity; columns 3 and 4) the negative and persistent effect of audits is also observed. More interestingly, if a taxpayer has reported an income larger than the average of other group members, this negatively and significantly impacts the level of the current reported income (negative horizontal reciprocity; Hypothesis 3). Conversely, if a taxpayer learns that he has been less honest than the average of other group members, he significantly increases his current reported income (positive horizontal reciprocity; Hypothesis 3). In both cases, the current reported income aims to come closer to the previous average of the reported income of other group members. Moreover, taxpayers only consider the average of income reported by other group members at the previous period (i.e., $t-1$ ). A long and persistent effect of this social information is not observed. Finally, reported estimates do not allow us to conclude whether being above the other group members' average has a stronger impact than being below it. Considering both vertical and horizontal inequities (i.e., from columns 5 to 8 ), we first note that the level of the tax rate no longer has a significant effect on reported income, which confirms our previous results according to which horizontal inequity dominates vertical inequity. This result can be explained by a convergence of taxpayer's decisions towards the mean. This argument holds only if taxpayers whose previous decisions are above other group members' average decrease the level of the next income they will report. Symmetrically, if the income they have reported is below other group members' average, they will report a higher income in the next period. These conditions of adjustment are confirmed by significant estimates both in the case of a disadvantageous tax rate (i.e., H-HV-I treatment; columns 5 and 6) and an advantageous tax rate (i.e., H-LV-I treatment; columns 7 and 8). However, a clear difference between these two settings has to be noted. In case of a disadvantageous inequity in tax rate, the difference in reported income has a significant and persistent effect on next reported income. This is all the more true for taxpayers who have reported a larger income than other group members' average. This result can be explained by the theoretical predictions established from the impact of both vertical and horizontal inequities. Indeed, we have seen that, when both inequities go in the same direction (i.e., both disadvantageous or both advantageous; columns 5 and 8) this may induce the same reciprocal behavior (i.e., negative or positive reciprocity). In this case, one can note that the effect of a difference between the reported income $X_{i}$ and the average reported income by other group members $\bar{X}_{-i}$ is stronger and more persistent than when inequities go in opposite 
directions (i.e., one disadvantageous and the other advantageous; columns 6 and 7). Hypothesis 4 is satisfied. All of these findings confirm that horizontal inequity dominates vertical inequity. Overall, socio-demographic characteristics and risk preferences rarely impact taxpayer's decisions. ${ }^{10}$ While the fact that pro-social preferences do not explain the level of reported income can be stunning at first sight, an explanation may be found from results reported in Table 5. Indeed, we observe that, in the current period, most taxpayers tend to adjust their reported income to match the previous average reported income of other group members, regardless of the type of pro-social preferences. This could suggest that the type of pro-social preferences inferred from the Bartling et al. (2009)'s procedure does not allow for a thin enough grid of pro-social preferences to highlight potentially different behaviors depending to the type of preferences and subsequent reactions to inequities.

\section{Conclusion}

In this experiment, we have analyzed whether vertical or horizontal inequity impacts reported income decisions, and whether they lead to reciprocal behaviors as stated by Schnellenbach (2010). We first found that disadvantageous inequity in tax rates leads to a decrease in the level of reported income while an advantageous inequity decreases the level of evasion. Second, when social information is provided, i.e., when taxpayers learn the average reported income of their other group members at the end of the period, most of them adjust their current reported income up or down to come closer to the previous reported mean. This occurs, regardless of whether the income they reported was above or below the mean. Finally, when the two types of inequities occur at the same time and go in the same direction, the effect of social information is very pronounced and persistent. Negative reciprocal behaviors can explain the spread of evasion in the case of disadvantageous inequities. Alternatively, in the case of advantageous inequities, this can be an explanation of a long trend of honest behavior. Conversely, when both inequities go in opposite directions, the horizontal inequity dominates the vertical one and leads to the corresponding reciprocal behavior. Here, an important point should be underlined in terms of the size of our groups. Whereas, intuitively, in small groups, it is clear that individual evasion activity matters directly to the rest of the group since it visibly modifies the

\footnotetext{
${ }^{10}$ Figure 3 in the Appendix 5 provides an overview of individuals risk preferences.
} 
collective outcome, one could question if the same occurs in large societies. But we do believe that our results could be useful in societies where tax evasion is commonly presented as a widespread practice. For instance in the French and Italian cases, it is common knowledge either that tax evasion is a "national sport" or at least that is generalized. ${ }^{11}$ In such cases, some conclusions can be drawn from our results. First, any communication on the extent of evasion and tax savings to be obtained from additional deterrent efforts may have the perverse effect to induce initially honest taxpayers to evade. Second, any communication on the equity of the system, jointly with any measures strengthening tax moral, for instance good examples of morally orientated taxpayers, could increase taxes collected in the long run.

\section{Acknowledgements}

The research reported here was funded by the University of Montpellier 1 under its Bonus Quality Research program. Experiments were run in the LABEX-EM (Laboratoire d'EXperimentation en Economie et Management) at the University of Rennes 1. We thank the members of the two laboratories for technical and practical assistance. We are grateful to the members of the LEEM (Laboratoire d'Economie Experimentale de Montpellier) for their comments on this work, participants at the AFSE and SABE conferences and the three referees for their guidance in revising this paper.

\section{References}

Allingham, M. G., \& Sandmo, A. (1972). Income tax evasion: A theoretical analysis. Journal of Public Economics, 1, 323-338.

Alm, J. (2012). Measuring, explaining, and controlling tax evasion: Lessons from theory, experiments, and field studies. International Tax and Public Finance, 19, 54-77.

\footnotetext{
${ }^{11}$ This so-called common knowledge may not be scientifically proven even if numerous econometric works deal with the extent of tax evasion in European countries (see Schneider \& Enste, 2002). Whereas in the Italian case, some figures could support this view, in the French case we refer to a popular belief or rumor that are developed because the government and administration do not at all communicate on the existence of tax evasion and its extent.
} 
Alm, J., Bahl, R., \& Murray, M. N. (1993a). Audit selection and income tax underreporting in the tax compliance game. Journal of Development Economics, 42, 1-33.

Alm, J., Jackson, B. R., \& McKee, M. (1993b). Fiscal exchange, collective decision institutions, and tax compliance. Journal of Economic Behavior \& Organization, 22, 285-303.

Alm, J., McClelland, G. H., \& Schulze, W. D. (1992). Why do people pay taxes? Journal of Public Economics, 48, 21-38.

Alm, J., \& McKee, M. (2004). Tax compliance as a coordination game. Journal of Economic Behavior \& Organization, 54, 297-312.

Arellano, M., \& Bond, S. (1991). Some tests of specification for panel data: Monte carlo evidence and an application to employment equations. Review of Economic Studies, 58, 277-97.

Barone, G., \& Mocetti, S. (2011). Tax morale and public spending inefficiency. International Tax and Public Finance, 18, 724-749.

Bartling, B., Fehr, E., Marechal, M. A., \& Schunk, D. (2009). Egalitarianism and competitiveness. American Economic Review, 99, 93-98.

Blundell, R., \& Bond, S. (1998). Initial conditions and moment restrictions in dynamic panel data models. Journal of Econometrics, 87, 115-143.

Bordignon, M. (1993). A fairness approach to income tax evasion. Journal of Public Economics, 52, 345-362.

Cowell, F. A. (1992). Tax evasion and inequity. Journal of Economic Psychology, 13, 521-543.

Cowell, F. A., \& Gordon, J. (1988). Unwillingness to pay : Tax evasion and public good provision. Journal of Public Economics, 36, 305-321.

Dell'Anno, R. (2009). Tax evasion, tax morale and policy maker's effectiveness. The Journal of Socio-Economics, 38, 988-997.

Dohmen, T., Falk, A., Huffman, D., Sunde, U., Schupp, J., \& Wagner, G. G. (2011). Individual risk attitudes: Measurement, determinants, and behavioral consequences. Journal of the European Economic Association, 9, $522-550$. 
Falkinger, J. (1995). Tax evasion, consumption of public goods and fairness. Journal of Economic Psychology, 16, 63-72.

Fehr, E., \& Gächter, S. (2000a). Cooperation and punishment in public goods experiments. American Economic Review, 90, 980-994.

Fehr, E., \& Gächter, S. (2000b). Fairness and retaliation: The economics of reciprocity. Journal of Economic Perspectives, 14, 159-181.

Feld, L., \& Frey, L. (2010). Tax evasion and the psychological tax contract. In J. Alm, J. Martinez-Vasquez, \& B. Torgler (Eds.), Developing Alternative Frameworks for Explaining Tax Compliance (pp. 74-94). Routledge: Routledge International Studies in Money and Banking.

Fischbacher, U. (2007). Z-tree: Zurich toolbox for ready-made economic experiments. Experimental Economics, 10, 171-178.

Fischbacher, U., Gächter, S., \& Fehr, E. (2001). Are people conditionally cooperative? evidence from a public goods experiment. Economics Letters, $71,397-404$.

Fortin, B., Lacroix, G., \& Villeval, M.-C. (2007). Tax evasion and social interactions. Journal of Public Economics, 91, 2089-2112.

Frey, B. S. (1997). A constitution for knaves crowds out civic virtues. Economic Journal, 107, 1043-53.

Frey, B. S., \& Torgler, B. (2007). Tax morale and conditional cooperation. Journal of Comparative Economics, 35, 136-159.

Gintis, H. (2000). Strong reciprocity and human sociality. Journal of Theoretical Biology, 206, 169-179.

Gordon, J. P. (1989). Individual morality and reputation costs as deterrents to tax evasion. European Economic Review, 33, 797-805.

Gouldner, A. (1960). The norm of reciprocity: A preliminary statement. American Sociology Review, 25, 161-178.

Greiner, B. (2004). The Online Recruitment System ORSEE 2.0 - A Guide for the Organization of Experiments in Economics. Working Paper Series in Economics 10 University of Cologne, Department of Economics. 
Hug, S., \& Spörri, F. (2011). Referendums, trust, and tax evasion. European Journal of Political Economy, 27, 120-131.

Kirchler, E. (2007). The Economic Psychology of Tax Behaviour. Cambrigde University Press.

Lefebvre, M., Pestieau, P., Riedl, A., \& Villeval, M. C. (2011). Tax Evasion, Welfare Fraud, and "The Broken Windows" Effect: An Experiment in Belgium, France and the Netherlands. IZA Discussion Papers 5609 Institute for the Study of Labor (IZA).

Myles, G. D., \& Naylor, R. A. (1996). A model of tax evasion with group conformity and social customs. European Journal of Political Economy, 12, 49-66.

Sandmo, A. (2005). The theory of tax evasion: A retrospective view. National Tax Journal, 58, 643-663.

Schneider, F., \& Enste, D. (2002). The Shadow Economy: An International Survey. Cambridge University Press.

Schnellenbach, J. (2010). Vertical and horizontal reciprocity in a theory of taxpayer compliance. In J. Alm, J. Martinez-Vasquez, \& B. Torgler (Eds.), Developing Alternative Frameworks for Explaining Tax Compliance (pp. 56-73). Routledge: Routledge International Studies in Money and Banking.

Spicer, M. W., \& Becker, L. A. (1980). Fiscal inequity and tax evasion: An experimental approach. National Tax Journal, 33, 171-175.

Torgler, B. (2003). Tax morale, rule-governed behaviour and trust. Constitutional Political Economy, 14, 119-140.

Torgler, B. (2007). Tax Compliance and Tax Morale. A Theoretical and Empirical Analysis. Cheltenham: Edward Elgar.

Traxler, C. (2010). Social norms and conditional cooperative taxpayers. European Journal of Political Economy, 26, 89-103.

Yitzhaki, S. (1974). Income tax evasion: A theoretical analysis. Journal of Public Economics, 3, 201-202. 


\section{Appendix 1 - Proofs of theoretical predictions}

\section{Vertical reciprocity}

Vertical reciprocity may occur in case of difference in tax rates (i.e., vertical inequity). The following psychological component accounts for this inequity:

$$
c=v_{i}(\phi)=1+\alpha_{i}\left(\theta_{i}-\theta_{j}\right) X_{i}
$$

In this context, taxpayer $i$ will choose $X_{i}$ to maximize his expected utility at period $t$ :

$$
\begin{aligned}
E U_{V I, i}= & (1-\rho)\left(W-\theta_{i} X_{i}\right)+\rho\left(W-\theta_{i} X_{i}-\left(W-X_{i}\right) \theta_{i} \pi\right) \\
& -\left(1+\alpha_{i}\left(\theta_{i}-\theta_{j}\right) X_{i}\right)
\end{aligned}
$$

Assuming first that taxpayer $i$ faces a higher tax rate than taxpayer $\mathrm{j}$, $\theta_{i}>\theta_{j}$. Because $\theta_{i}>\theta_{j}$, then (8) represents the psychological cost related to the difference in tax rates. It is straightforward to show that:

1. $\frac{\partial v_{i}(\phi)}{\partial \phi}>0$ : When the difference in tax rates increases, $(\phi)$, the related cost $v_{i}(\phi)$ and the disutility for taxpayer $i$ also increase.

2. $\frac{\partial v_{i}(\phi)}{\partial X_{i}}>0$ : The cost borne by taxpayer $i, v_{i}(\phi)$, increases along with the income he reports.

As a consequence, when taxpayer $i$ suffers from the inequity, he will underreport his income to maximize his expected utility (9) if his sensitivity to the inequity is high enough, i.e.,

$$
\overline{\alpha_{i}}>\frac{(-1+\pi \rho) \theta_{i}}{\theta_{i}-\theta_{j}}
$$

From this threshold, the more sensitive the taxpayer $i$ is to difference in tax rates the more the taxpayer $i$ suffers from the inequity and decreases the level of reported income to express his discontent or anger towards the government (negative vertical reciprocity).

Symmetrically, when taxpayer $i$ has a lower tax rate than taxpayer $j$, he benefits from an advantageous inequity in tax rates. In his expected utility 
function $(9), v_{i}(\phi)$ appears as a gain arising from the inequity. It results the following behavioral patterns:

1. $\frac{\partial v_{i}(\phi)}{\partial \phi}>0$ : When the difference in tax rates increases, $(\phi)$, the related gain $v_{i}(\phi)$ as well as the expected utility of taxpayer $i$ increase.

2. $\frac{\partial v_{i}(\phi)}{\partial X_{i}}>0$ : The gain in utility rises along with reported income.

As a consequence, when taxpayer $i$ benefits from the inequity, he will honestly declare his income to maximize his expected utility (9). This result holds for $\forall \alpha_{i}>0$ (positive vertical reciprocity).

\section{Horizontal reciprocity}

Horizontal reciprocity may be expressed when inequity is due to difference in reported incomes between taxpayer $i$ and the average of other group members (i.e., horizontal inequity). The following psychological component accounts for this inequity:

$$
c=\eta_{i}(\xi)=1+\delta_{i}\left(X_{i, t-1}-\bar{X}_{-i, t-1}\right) X_{i, t}
$$

In this context, taxpayer $i$ will choose $X_{i}$ to maximize his expected utility at period $t$ :

$$
\begin{aligned}
E U_{H I, i, t}= & (1-\rho)\left(W-\theta X_{i, t}\right)+\rho\left(W-\theta X_{i, t}-\left(W-X_{i, t}\right) \theta \pi\right) \\
& -\left(1+\delta_{i}\left(X_{i, t-1}-\bar{X}_{-i, t-1}\right) X_{i, t}\right)
\end{aligned}
$$

Assuming first that taxpayer $i$ has reported an income higher than his other group members on average, i.e., $X_{i, t-1}>\bar{X}_{-i, t-1}$. Taxpayer $i$ suffers from this inequity measured through the psychological cost (11). It is straightforward to show that:

1. $\frac{\partial \eta_{i}(\xi)}{\partial \xi}>0$ : When the difference between taxpayer $i$ 's reporting decision at period $t-1$ and the average reported income of his other group members at the same period increases, $\xi$, taxpayer $i$ 's related cost, $\eta_{i}(\xi)$, and disutility, increase.

2. $\frac{\partial \eta_{i}(\xi)}{\partial X_{i, t}}>0$ : The psychological cost, $\eta_{i}(\xi)$, is increasing along with reported income. 
As a consequence, when taxpayer $i$ suffers from the inequity, at the next period he will under-report his income to maximize his expected utility (12) and to come closer to his group average, if his sensitivity to the inequity is high enough, i.e.,

$$
\bar{\delta}_{i}>\frac{(-1+\pi \rho) \theta}{X_{i, t-1}-\bar{X}_{-i, t-1}}
$$

From this threshold, the more sensitive taxpayer $i$ is to differences in reported incomes with the average of other group members, the more the taxpayer $i$ suffers from the inequity and decreases the level of his next reported income (negative horizontal reciprocity). So, in case of disadvantageous inequity, taxpayer $i$ decides to evade to minimize his psychological cost and to diminish the gap with the average decision of his other group members observed at the previous period.

Let us turn now to the case where taxpayer $i$ has reported a lower income than the average of his other group members, i.e., $X_{i, t-1}<\bar{X}_{-i, t-1}$. Here he benefits from an advantageous inequity in terms of reported income measured by (11). It follows that:

1. $\frac{\partial \eta_{i}(\xi)}{\partial \xi}>0$ : When the difference between taxpayer $i$ 's reported income and the average reported income of his other group members increases, $\xi$, taxpayer $i$ 's related gain, $\eta_{i}(\xi)$, and his utility increase.

2. $\frac{\partial \eta_{i}(\xi)}{\partial X_{i, t}}>0$ : The gain in utility rises along with reported income.

As a consequence, when taxpayer $i$ benefits from the inequity, he will increase his next reported income to maximize his expected utility (12) and to come closer to his group average (positive horizontal reciprocity). This result holds for $\forall \delta_{i}>0$.

\section{Appendix 2 - Theoretical predictions from numerical simulations}

Here, we detail the way the parameters of the experiment were chosen. In order to observe reciprocal reactions in the tax game, we need as a benchmark a full contribution environment. To that end, we decided to set an initial income $W=100$ for all subjects and groups of 6 participants to allow for an audit probability $\rho=\frac{1}{3}$ in line with the literature. As a consequence, the 
fine rate needed to be above than $300 \%$. We chose $\pi=350 \%$. Finally, we decided to set $\theta=30 \%$ to allow for realistic variations in tax rates.

\section{Vertical reciprocity}

In the case of vertical inequity, taxpayer $i$ maximizes his expected utility function (9). From that, we first assume that taxpayer $i$ has a higher tax rate than taxpayer $j$ in his group (i.e., disadvantageous vertical inequity, HV-I treatment). In this case, we set $\theta_{i}=30 \%$ and $\theta_{j}=20 \%$.

The maximization of the expected utility function (9) that corresponds to fully honest behavior in the absence of inequity and full evasion behavior in the case of a disadvantageous inequity (i.e., negative vertical reciprocity) requires that the following condition be respected:

$$
\pi<\frac{\theta_{i}+\alpha_{i} \theta_{i}-\alpha_{i} \theta_{j}}{\rho \theta_{i}}
$$

Given our numerical parameters, it follows that fully honest behaviors in the benchmark treatment and full evasion behaviors in the HV-I treatment will be observed if:

$$
\begin{aligned}
\overline{\alpha_{i}} & >\frac{(-1+\pi \rho) \theta_{i}}{\theta_{i}-\theta_{j}} \\
\overline{\alpha_{i}} & >0.5
\end{aligned}
$$

Symmetrically, in case of advantageous vertical inequity (i.e., LV-I treatment), we set $\theta_{i}=30 \%$ and $\theta_{j}=40 \%$. It results that the maximization of the expected utility function (9) leading to fully honest behavior, both in the absence of inequity and in the case of an advantageous inequity (i.e., positive vertical reciprocity), implies:

$$
\pi>\frac{\theta_{i}+\alpha_{i} \theta_{i}-\alpha_{i} \theta_{j}}{\rho \theta_{i}}
$$

With our numerical values, we obtain:

$$
\underline{\alpha_{i}}>-0.5
$$




\section{Horizontal reciprocity}

In case of horizontal inequity, all taxpayers have the same tax rate $\theta=$ $30 \%$. Taxpayer $i$ maximizes his expected utility function (12). To determine the numerical values of $\delta_{i}$ that lead to an increase or decrease in reported income, we needed to set numerical values for $X_{i, t-1}$ and $\bar{X}_{-i, t-1}$. We arbitrarily set $X_{i, t-1}=100$ and $\bar{X}_{-i, t-1}=50$ in the case of disadvantageous horizontal inequity and the reverse in the case of advantageous horizontal inequity. It is noteworthy that various other numerical simulations have been conducted and lead to few variations in the value of $\delta_{i}$ to obtain the behavioral predictions that follow.

From now on, we first assume that taxpayer $i$ has reported a higher income than the average of his group i.e., $X_{i, t-1}>\bar{X}_{-i, t-1}$. The maximization of his utility function (12) corresponds to fully honest behavior in the absence of inequity and full evasion behavior in the case of disadvantageous inequity (i.e., negative horizontal behavior) if:

$$
\pi<\frac{\theta+\delta_{i} X_{i, t-1}-\delta_{i} \bar{X}_{-i, t-1}}{\rho \theta}
$$

Given our numerical parameters, we obtain:

$$
\begin{aligned}
\overline{\delta_{i}} & >\frac{(-1+\pi \rho) \theta}{X_{i, t-1}-\bar{X}_{-i, t-1}} \\
\overline{\delta_{i}} & >0.001
\end{aligned}
$$

Symmetrically, if taxpayer $i$ has reported an income smaller than the average of his other group members, the fully honest behavior observed both in the benchmark treatment and in the case of advantageous horizontal inequity (i.e., positive horizontal reciprocity) is noticed if:

$$
\pi>\frac{\theta+\delta_{i} X_{i, t-1}-\delta_{i} \bar{X}_{-i, t-1}}{\rho \theta}
$$

With the used numerical values, the behavioral prediction of fully honest behavior in the two settings is observed if: 


$$
\underline{\delta_{i}}>-0.001
$$

\section{Vertical and horizontal inequities}

When both horizontal and vertical inequities exist at the same time, some behavioral patterns are easy to predict while others are the result of opposite incentives. 4 conceivable situations are possible:

1. Disadvantageous vertical inequity and disadvantageous horizontal inequity: The former leads to full evasion behavior if $\overline{\alpha_{i}}>0.5$ and the latter leads to full evasion behavior if $\overline{\delta_{i}}>0.001$. It follows that, if $\overline{\alpha_{i}}>0.5$ and $\overline{\delta_{i}}>0.001$, then full evasion behavior (and so negative reciprocity) will be observed.

2. Advantageous vertical inequity and advantageous horizontal inequity: The former leads to fully honest behavior if $\alpha_{i}>-0.5$ and the latter leads to fully honest behavior if $\delta_{i}>-0.001$. It follows that, if $\underline{\alpha_{i}}>-0.5$ and $\underline{\delta_{i}}>-0.001$, then fully honest behavior (and so positive reciprocity) will be observed. This is always true since we have supposed that $\alpha>0$ and $\delta>0$.

3. Disadvantageous vertical inequity and advantageous horizontal inequity: While the first inequity leads to full evasion behavior, the second induces taxpayers to increase the amount of income they report. So the two inequities imply reciprocal behaviors in opposite directions and no clear behavioral pattern may be predicted thereafter.

4. Advantageous vertical inequity and disadvantageous horizontal inequity: While the first inequity leads to fully honest behavior, the second induces taxpayers to decrease the amount of income they report. Again no clear behavioral pattern may be predicted here.

\section{Appendix 3 - Decisions sheet for the risk game experiment}

[Table 7 about here.]

\section{Appendix 4 - Decisions sheet for the inequity game experiment}

[Table 8 about here.] 


\section{Appendix 5 - Decisions in the risk game}

[Figure 3 about here.]

\section{Appendix 6 - Instructions for the tax game experiment}

The experiment in which you are about to take part aims at studying how individuals make their decisions. If you carefully read these instructions, you will have the opportunity to leave with a non-negligible amount of money. During the experiment, you are not allowed to communicate. If you violate this rule, you will be excluded from the experiment and you will not be paid. If you have questions, raise your hand and we will come to answer you in private. All your answer will be treated anonymously and will be collected through the computer network. You will indicate your choices on the computer you are seated in front of, and the computer will inform you about your earnings in experimental points. The sum you will earn during the experiment will be paid by check at the end of the experiment, following the conversion rule: 38 Points $=1$ Euro. We will add a participation fee of 3 Euros to this earned amount.

\section{General framework of the experiment}

At the beginning of the experiment you will be assigned to a group of 6 people, randomly chosen among the 24 people present in the room. Group composition will remain unchanged until the end of the experiment. You will thus always interact with the same 5 other people. This experiment is composed of 20 identical periods.

\section{Schedule of one period}

Each period is composed of three steps.

\section{Step 1: Income report}

At the beginning of each period, you will be given an income of 100 points. This income is the same for all participants in the experiment and will be identical among periods. Once you learn your income, you will have to report it. You are free to report what you want using a whole number between 0 and 100. You can report $0,1,2, \ldots, 98,99$ up to 100 points. A screen will summarize the different information available to help you to make your decision, as shown below:

[Figure 4 about here.] 


\section{Step 2: Deduction and control}

- Deduction on reported income: The reported income in step 1 will be subject to a deduction. The amount deducted is calculated as follows:

Deduction on reported income $=$ (reported income $\mathrm{x}$ rate of deduction)

The deduction rate is the same for all participants and for all of the 20 periods, i.e. $30 \%(0,3)$. This way, if you declare 100 points, 30 points will be deducted $(100 \times 0,3=30)$.

[HV-I: The deduction rate can take two values: Half of the group members (3 people out of 6 ) will face a 30\% (0,3) rate, and the second half (the 3 remaining members) will face a $20 \%(0,2)$ rate. Each individual will face the same rate for the 20 periods.] [LV-I: The deduction rate can take two values: Half of the group members (3 people out of 6) will face a $30 \%(0,3)$ rate, and the second half (the 3 remaining members) will face a $40 \%(0,4)$ rate. Each individual will face the same rate for the 20 periods.]

- Control of reported income and penalty: At the end of step 1, the computer controls the reported income of some participants. More precisely, 2 people from each group are randomly drawn by the computer to be controlled. This control aims at comparing initial and reported incomes. So:

- If you are controlled and you have reported an income lower than your initial income, a penalty will be charged. This penalty is calculated as follows:

$$
\begin{gathered}
\text { Penalty }=(\text { initial income }- \text { reported income }) \mathrm{x} \text { deduction } \\
\text { rate } \mathrm{x} \text { penalty rate }
\end{gathered}
$$

The penalty rate is the same for all participants and all periods. It is equal to $350 \%(3,5)$.

- If you are controlled and you have reported totally your initial income, you will not be charged any penalty.

- If you are not controlled, no penalty will be charged.

- Calculus of earnings of the period: In each period, your earnings are calculated as follows: 


$$
\begin{gathered}
\text { Earnings }=\text { initial income }-(\text { reported income } \mathrm{x} \text { deduction rate }) \text { - } \\
\text { potential penalty }
\end{gathered}
$$

\section{Step 3 : History}

At the end of each period, you will be reminded about the following: your initial income, reported income, whether you have been audited, potentially paid penalties and your earnings at the end of this period [H-I and the average reported income of the other members of your group]. You are not able to learn decisions made by others or their earnings. In the same way, others are unable to learn your decisions and earnings. In addition, you cannot learn choices or gains of other groups. This history is presented as follows:

[Figure 5 about here.]

After reading this information, a new period, identical on all points, will start and you will interact with the same people.

Payment: 5 of the 20 periods will be randomly chosen at the end of the experiment for payment and will be the same for all participants. We will sum the earnings over the 5 periods, plus the 3 Euros participation fee.

3. Examples

- Example 1: You have an income of 100 points and the deduction rate is 0,3 . If you decide to fully report the 100 points, your earnings are:

- 100 (your income) - 0,3 x 100 (deducted amount) $=70$ points if you are not controlled.

- 100 (your income) - 0,3 x 100 (deducted amount) $=70$ points if you are controlled. The penalty is effectively not charged because you have totally reported your income.

- Example 2: You have an income of 100 points and the deduction rate is 0,3 . If you decide to report half of your income, i.e., 50 points, yours earnings are:

- 100 (your income) - 0,3 x 50 (amount deducted) $=100-15$ $=85$ points if you are not controlled.

- 100 (your income) - 0,3 x 50 (deducted amount) - (100 - 50) $\mathrm{x} 0,3 \times 3,5$ (penalty) $=100-15-52,5=32,5$ points if you are controlled. 
Figure 1: Average reported income per experimental treatment
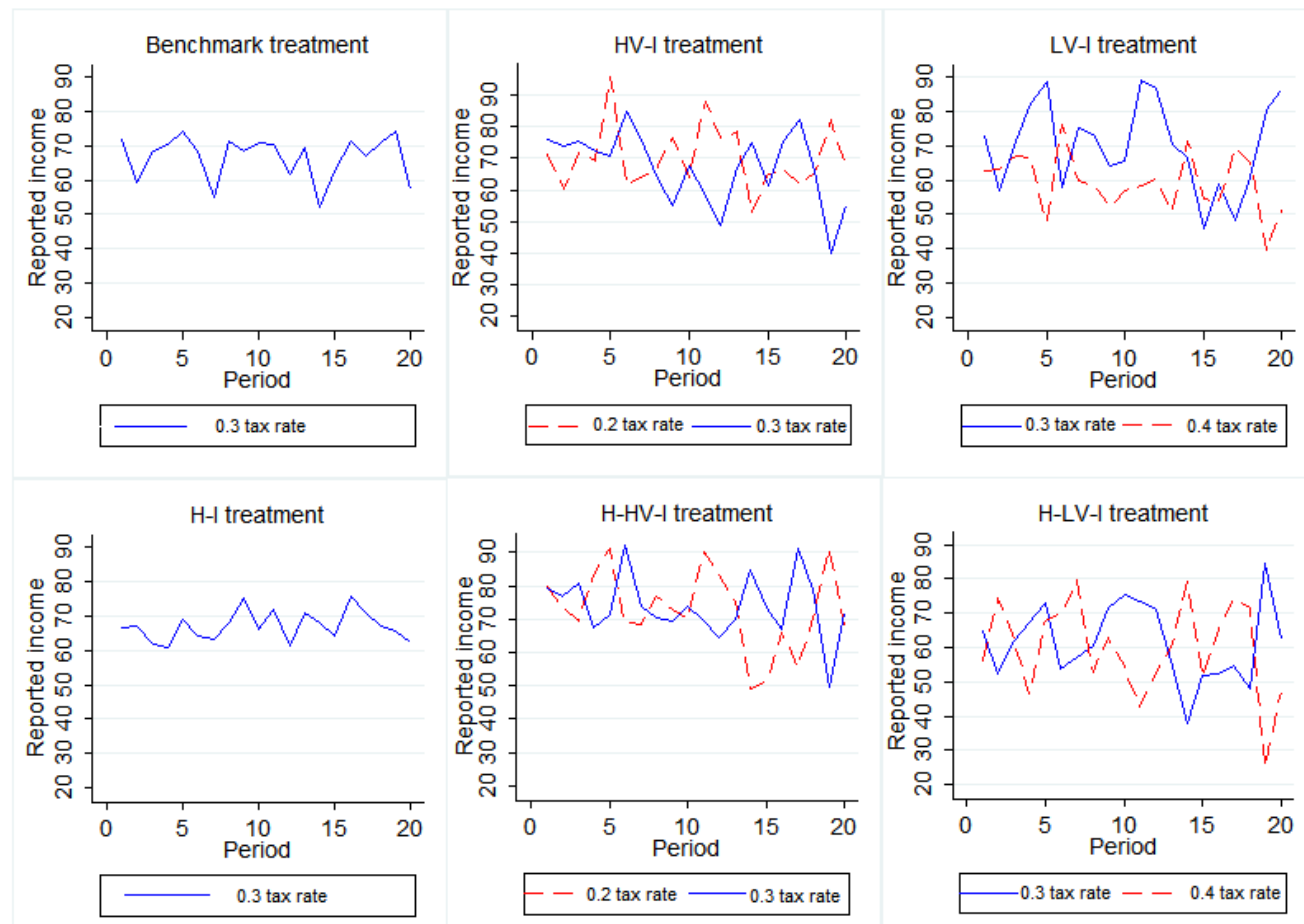
Figure 2: Average reported income by taxpayers with a 30\% tax rate under social information

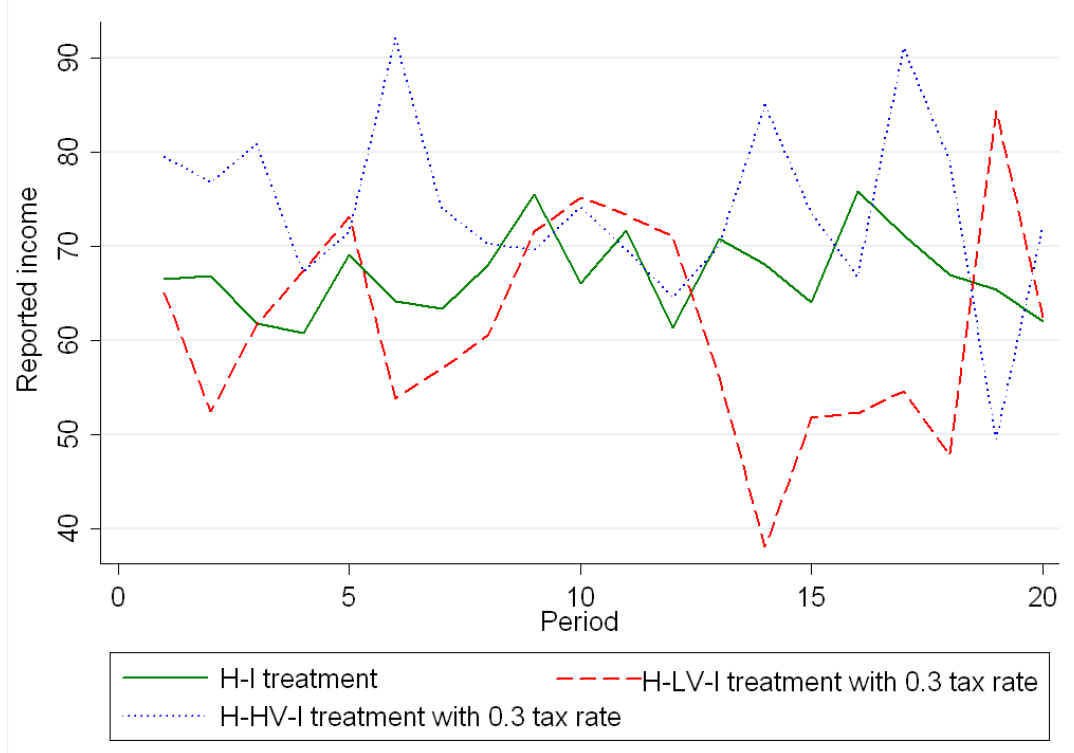


Figure 3: Overview of decisions in the risk game per experimental treatment
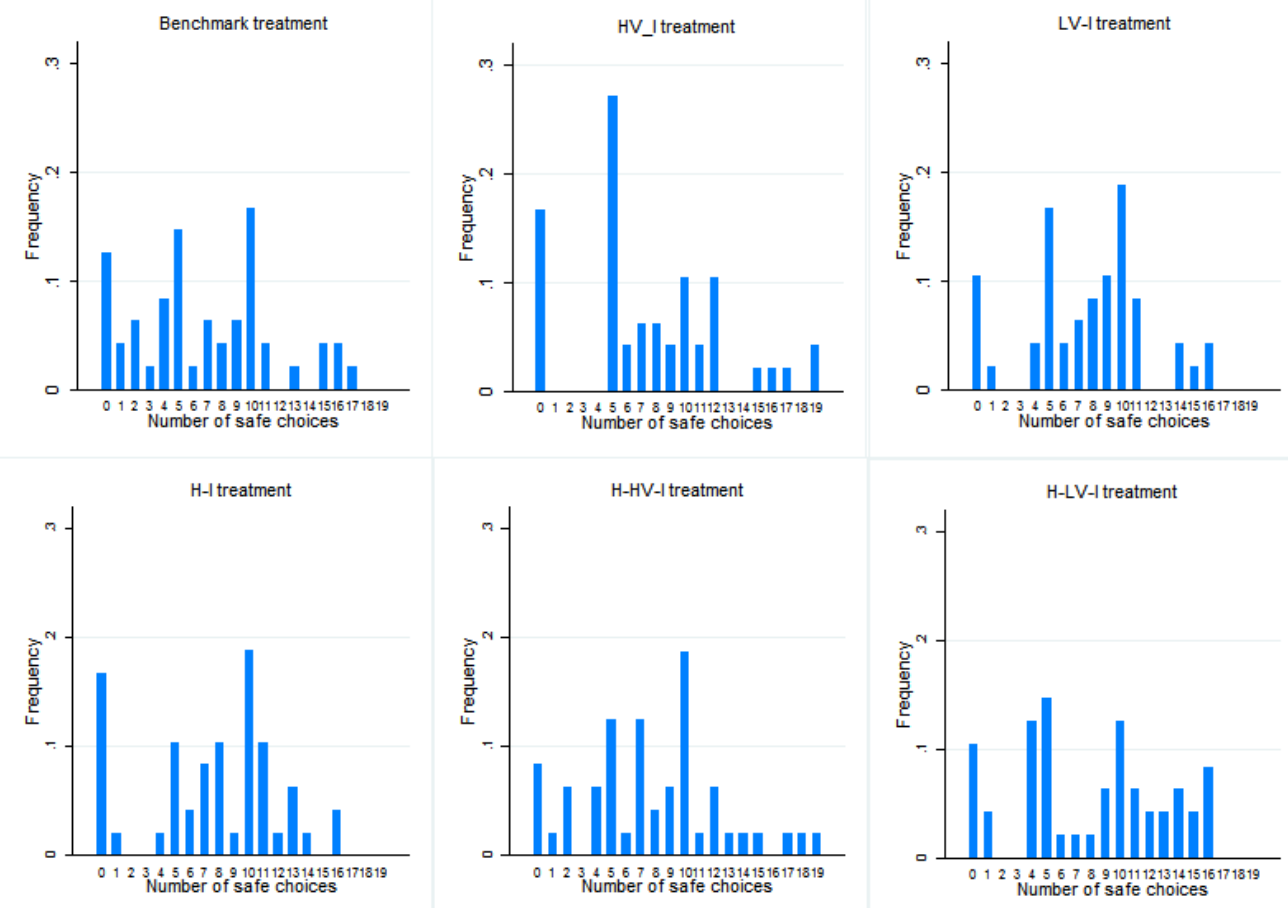
Figure 4: First computer screen for tax game experiment

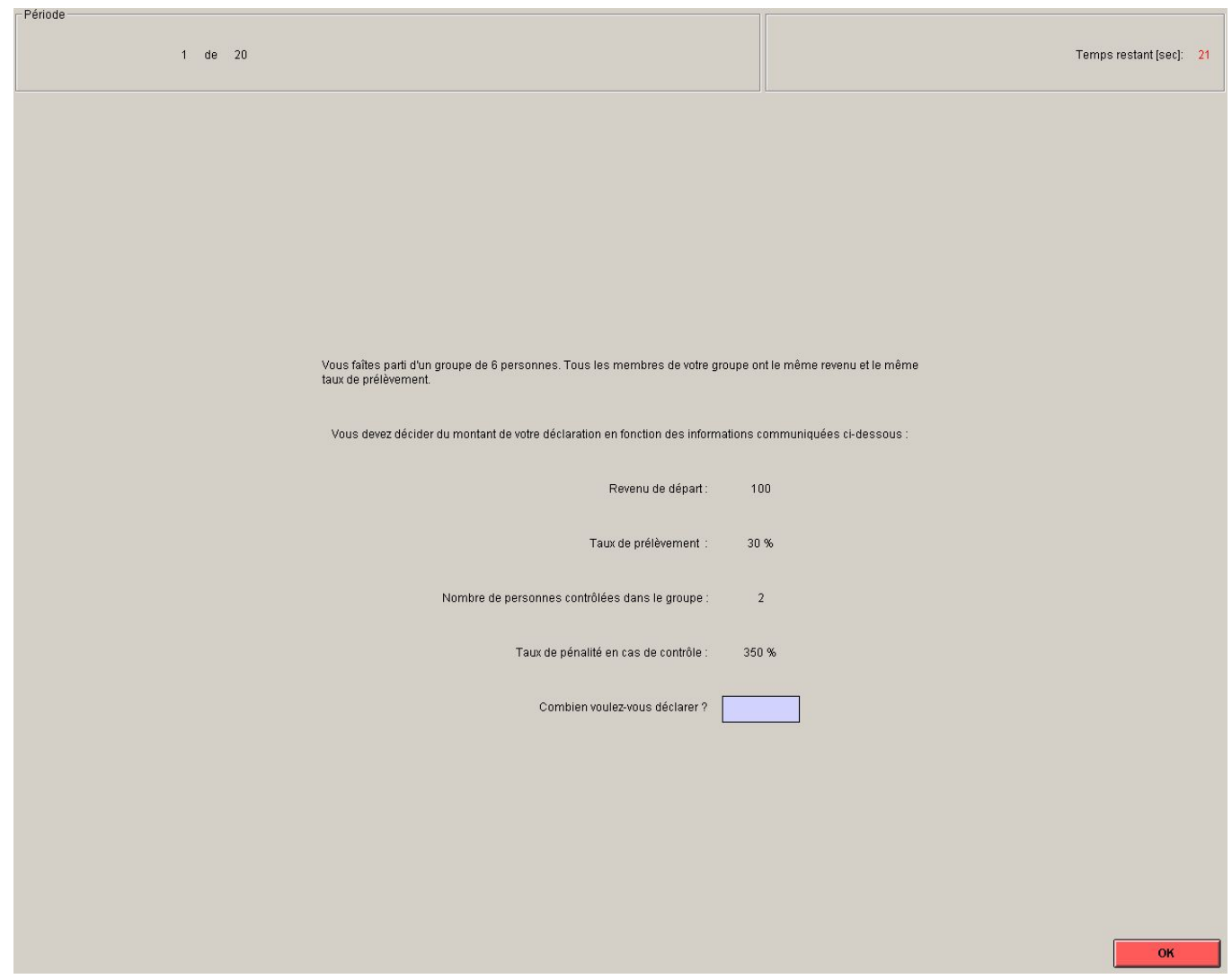


Figure 5: Second computer screen for the tax game experiment

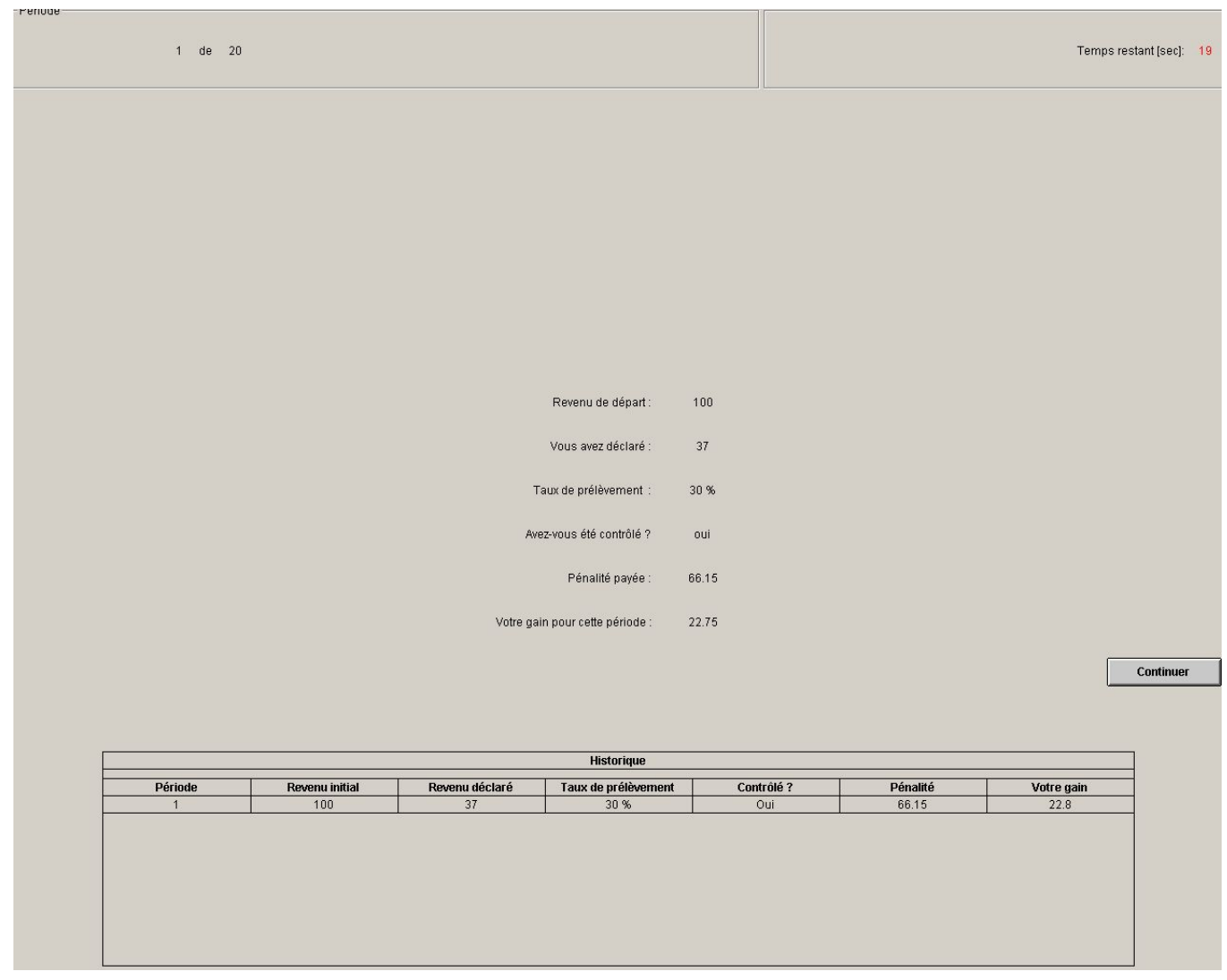


Table 1: Theoretical predictions

\begin{tabular}{|c|c|c|}
\hline Type of inequity & & Theoretical predictions for taxpayer $i$ at period $t$ \\
\hline \multicolumn{3}{|r|}{ W } \\
\hline & $\theta_{i}>\theta_{j}$ & Full evasion ; Negative reciprocity \\
\hline & $\theta_{i}<\theta_{j}$ & Full honesty ; Positive reciprocity \\
\hline & $X_{i, t-1}>\bar{X}_{-}$ & Decrease in reported income ; Negative reciprocity \\
\hline & $X_{i, t-1}<\bar{X}_{-i, t-1}$ & Increase in reported income ; Positive reciprocity \\
\hline Doun vertical \& Horizontal & $\theta \cdot>\theta \cdot \& X$. & Full evasion · Neorative recinrocity \\
\hline & $\begin{array}{l}\theta_{i}>\theta_{j} \& \Lambda_{i, t-1}>\Lambda_{-i, t-1} \\
\theta_{i}>\theta_{j} \& X_{i, t-1}<\bar{X}_{-i, t-1}\end{array}$ & Indeterminate \\
\hline & $\theta_{i}<\theta_{j} \& X_{i, t-1}>\bar{X}_{-i, t-1}^{-i, t-1}$ & Indeterminate \\
\hline & $\theta_{i}<\theta_{j} \& X_{i, t-1}<\bar{X}_{-i, t-1}$ & Full honesty ; Positive reciprocity \\
\hline
\end{tabular}


Table 2: Summary of parameters per experimental treatment

\begin{tabular}{lccccc}
\hline \hline Treatments & Income & Tax rates & Audit & Fine & $\begin{array}{c}\text { Social } \\
\text { information }\end{array}$ \\
\hline Benchmark & 100 & $30 \%$ & $1 / 3$ & $350 \%$ & Not provided \\
HV-I & 100 & $30 \%-20 \%$ & $1 / 3$ & $350 \%$ & Not provided \\
LV-I & 100 & $30 \%-40 \%$ & $1 / 3$ & $350 \%$ & Not provided \\
H-I & 100 & $30 \%$ & $1 / 3$ & $350 \%$ & Provided \\
H-HV-I & 100 & $30 \%-20 \%$ & $1 / 3$ & $350 \%$ & Provided \\
H-LV-I & 100 & $30 \%-40 \%$ & $1 / 3$ & $350 \%$ & Provided \\
\hline
\end{tabular}


Table 3: Average sample statistics of our subjects pool

\begin{tabular}{lc}
\hline & Frequency \\
\hline Age & \\
18 and less & 36.46 \\
19 & 31.60 \\
20 & 20.14 \\
21 and more & 11.80 \\
Gender & \\
Men & 50.00 \\
Women & 50.00 \\
Level of studies & \\
First year & 55.21 \\
Higher degree & 44.79 \\
Discipline & \\
Economics & 68.75 \\
Other & 31.25 \\
Job activities & \\
Yes & 15.97 \\
No & 84.03 \\
\hline
\end{tabular}


Table 4: Descriptives statistics per experimental treatment

\begin{tabular}{|c|c|c|c|c|c|}
\hline Treatments & Subjects & $\mathrm{N}$ & Mean reported income & $\%$ of fully honest & $\%$ of full evaders \\
\hline Benchmark & & 960 & $66.74(41.29)$ & 48.54 & 19.58 \\
\hline \multirow{3}{*}{ HV-I } & All & 960 & $66.37(41.89)$ & 49.16 & 20.00 \\
\hline & With $30 \%$ tax rate & 480 & $61.93(42.60)$ & 42.08 & 22.08 \\
\hline & With $20 \%$ tax rate & 480 & $70.81(40.74)$ & 56.25 & 17.92 \\
\hline \multicolumn{6}{|l|}{ LV-I } \\
\hline & All & 960 & $64.65(40.96)$ & 44.48 & 18.02 \\
\hline & With $30 \%$ tax rate & 480 & $70.04(39.58)$ & 50.21 & 16.04 \\
\hline & With $40 \%$ tax rate & 480 & $59.27(41.63)$ & 38.75 & 20.00 \\
\hline H-I & & 960 & $66.99(39.25)$ & 42.29 & 15.62 \\
\hline \multicolumn{6}{|l|}{ H-HV-I } \\
\hline & All & 960 & $73.32(39.44)$ & 57.39 & 14.48 \\
\hline & With $30 \%$ tax rate & 480 & $73.86(38.40)$ & 55.83 & 13.75 \\
\hline & With $20 \%$ tax rate & 480 & $72.78(40.51)$ & 58.96 & 15.21 \\
\hline \multicolumn{6}{|l|}{ H-LV-I } \\
\hline & All & 960 & $60.64(42.19)$ & 39.17 & 20.73 \\
\hline & With $30 \%$ tax rate & 480 & $61.51(42.39)$ & 38.54 & 20.00 \\
\hline & With $40 \%$ tax rate & 480 & $59.78(42.02)$ & 39.79 & 21.46 \\
\hline
\end{tabular}

Notes: Standard deviation in parentheses. 


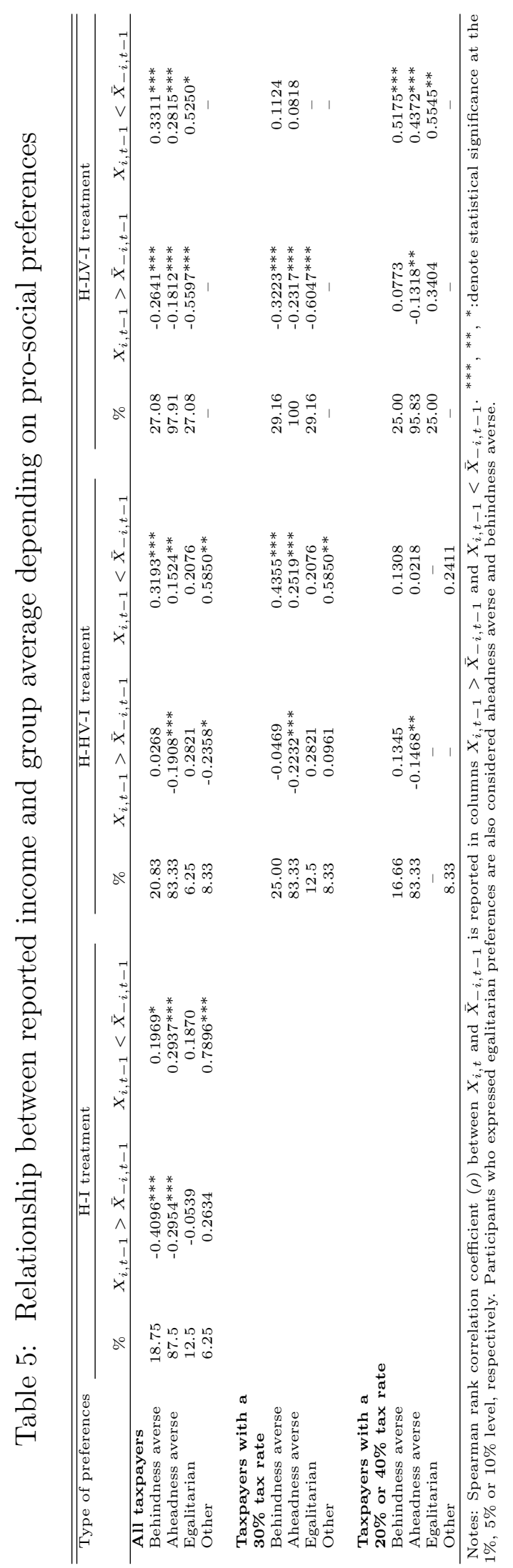




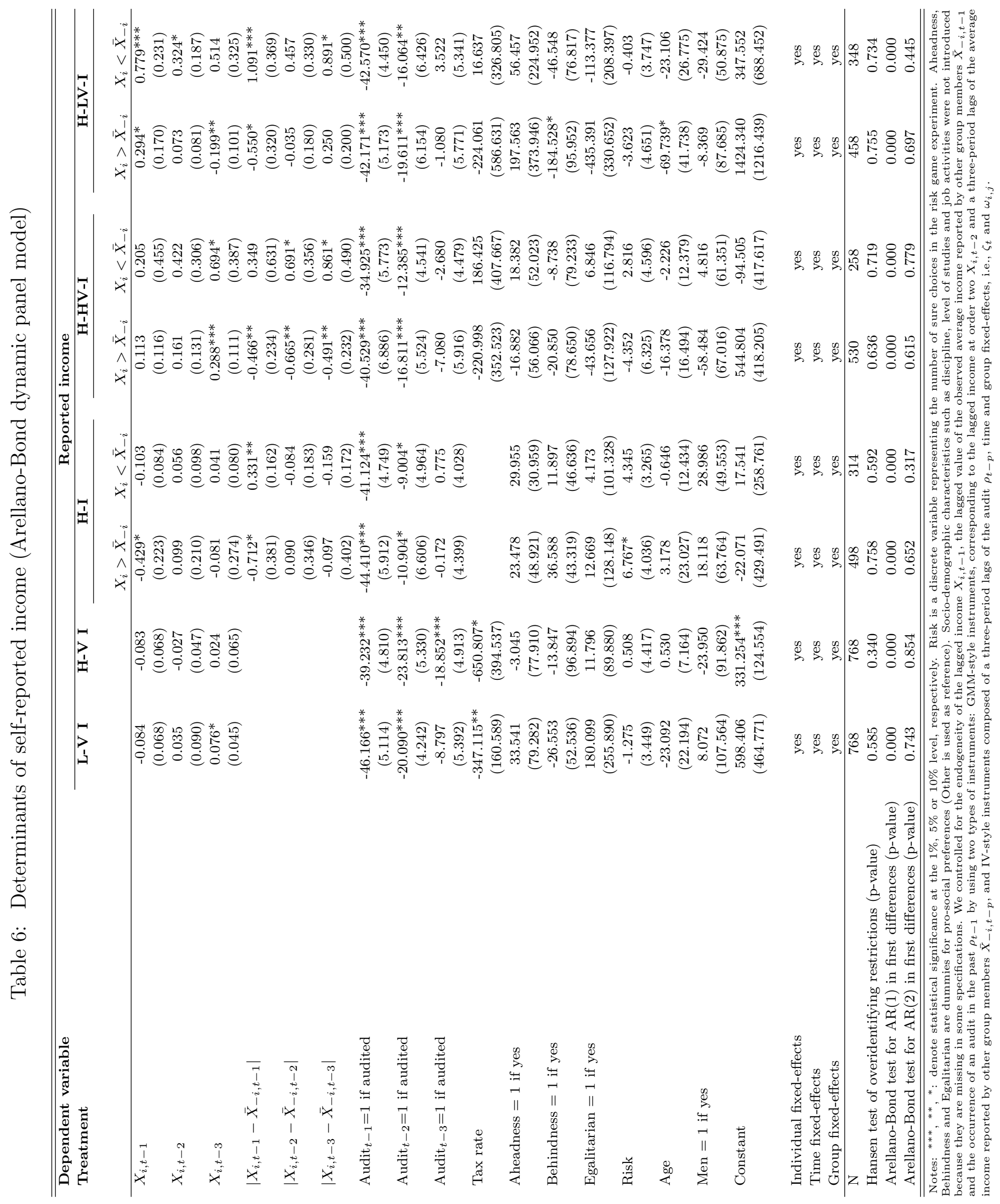


Table 7: The 21 decisions in the risk game experiment

\begin{tabular}{lcc}
\hline \hline Situations & Option A $\begin{array}{c}\text { Choose } \\
\text { Right or Left }\end{array}$ \\
\hline Situation 1 & 0 & $50 \%$ to get 0 and $50 \%$ to get 30 \\
Situation 2 & 1 & $50 \%$ to get 0 and $50 \%$ to get 30 \\
Situation 3 & 2 & $50 \%$ to get 0 and $50 \%$ to get 30 \\
Situation 4 & 3 & $50 \%$ to get 0 and $50 \%$ to get 30 \\
Situation 5 & 4 & $50 \%$ to get 0 and $50 \%$ to get 30 \\
Situation 6 & 5 & $50 \%$ to get 0 and $50 \%$ to get 30 \\
Situation 7 & 6 & $50 \%$ to get 0 and $50 \%$ to get 30 \\
Situation 8 & 7 & $50 \%$ to get 0 and $50 \%$ to get 30 \\
Situation 9 & 8 & $50 \%$ to get 0 and $50 \%$ to get 30 \\
Situation 10 & 9 & $50 \%$ to get 0 and $50 \%$ to get 30 \\
Situation 11 & 10 & $50 \%$ to get 0 and $50 \%$ to get 30 \\
Situation 12 & 11 & $50 \%$ to get 0 and $50 \%$ to get 30 \\
Situation 13 & 12 & $50 \%$ to get 0 and $50 \%$ to get 30 \\
Situation 14 & 13 & $50 \%$ to get 0 and $50 \%$ to get 30 \\
Situation 15 & 14 & $50 \%$ to get 0 and $50 \%$ to get 30 \\
Situation 16 & 15 & $50 \%$ to get 0 and $50 \%$ to get 30 \\
Situation 17 & 16 & $50 \%$ to get 0 and $50 \%$ to get 30 \\
Situation 18 & 17 & $50 \%$ to get 0 and $50 \%$ to get 30 \\
Situation 19 & 18 & $50 \%$ to get 0 and $50 \%$ to get 30 \\
Situation 20 & 19 & $50 \%$ to get 0 and $50 \%$ to get 30 \\
\hline
\end{tabular}


Table 8: The 4 situations in the inequity game

\begin{tabular}{lccccc}
\hline \hline Situations & \multicolumn{2}{c}{ Distribution A } & Choose & \multicolumn{2}{c}{ Distribution B } \\
& Your payoff & Other's payoff & Right or Left & Your payoff & Other's payoff \\
\hline Situation 1 & 10 & 10 & & 10 & 6 \\
Situation 2 & 10 & 10 & & 16 & 4 \\
Situation 3 & 10 & 10 & & 10 & 18 \\
Situation 4 & 10 & 10 & & 11 & 19 \\
\hline
\end{tabular}

